\title{
Reliability assessment of the behavior of reinforced and/or prestressed concrete beams sections in shear failure
}

\author{
Karim Benyahi, Mohand Said Kachi, Youcef Bouafia \\ Department of civil engineering, Mouloud Mammeri University, 15000 Tizi Ou₹ou, Algeria. \\ karim.benyabi@ummto.dv, bttps://orcid.org/0000-0003-2033-6217 \\ kachi_ms@yahoo.fr,youcef.bonafia2012@yahoo.com
}

Salma Barboura, Jia Li

C.N.R.S. LSPM - UPR 3407 Laboratory, Paris 13 university, Paris, France.

salma.barboura@univ-paris13.fr,jia.li@univ-paris13.fr

\begin{abstract}
The object of this article is to be able to simulate the behavior of reinforced and/or prestressed concrete beam's section in the shear loading through a model allowing the evaluation of nonlinear strains caused by shear, while taking into account the real behavior of the materials. In this approach, we are often confronted with problems of modeling uncertainties linked to some insufficiencies of the mechanical model allowing to describe the physical phenomena in a realistic way. For that, it is necessary to use a reliability model making it possible to evaluate their probability of failure, by establishing failure curves according to the different transition zones of the limit state curve of the nonlinear behavior in the shear loading up to at section failure of reinforced and/or prestressed concrete beams. In this work, we also propose a coupling of the reliability method by response surface to carry out the reliability optimization on complex mechanical models, where the mechanical and reliability models developed have been implemented on the Fortran. This allows the estimation in an efficient way of the different reliability characteristics according to each transition zone from the limit state curve to the real behavior until failure in the shear loading.
\end{abstract}

KEYWORDS: Nonlinearity; Reinforced concrete; Shear; Reliability; Probability of failure.

\section{OPEN $\bigcirc$ ACCESS}

Citation: Benyahi, K., Kachi, MS., Bouafia, Y., Barboura, S., Li, J., Reliability assessment of the behavior of reinforced and/or prestressed concrete beams sections in shear failure, Frattura ed Integrità Strutturale, 57 (2021) 195-222.

Received: 03.04 .2021

Accepted: 06.06.2021

Published: 01.07.2021

Copyright: (C) 2021 This is an open access article under the terms of the CC-BY 4.0 , which permits unrestricted use, distribution, and reproduction in any medium, provided the original author and source are credited.

\section{INTRODUCTION}

I $\mathrm{n}$ order to best estimate the shear loading behavior of elements of reinforced and prestressed concrete structures, several studies have been considered by the world, so knowledge of the real behavior of the constituent materials makes it possible to predict their behavior in a global manner. Research that has been carried out to improve our understanding of the shear loading behavior is summarized below. Collins [1] was the first to propose a theoretical 
approach to the compression field, using stress-strain relationships for cracked concrete applied to members with shear reinforcement, where he made an assumption that after cracking, the concrete does not support a tensile force which leads to a diagonal compression field. Vicchio and Collins [2,3] proposed a model making it possible to predict the loadstrain response for reinforced concrete elements, subjected to a normal force and a shear force. Several equilibrium and compatibility relationships have been developed as a function of the average stresses and strains. Several observations have been made; cracked concrete subjected to high tensile forces in the direction normal to the compressive direction is lower in compression, and significant tensile forces have been observed in concrete between cracks. Although many studies have been reviewed on the shear behavior of reinforced and / or prestressed concrete structures, the proposed models (Bažant and Kazemi [4]; Bentz et al. [5]; Carbone et al. [6]; Hsu and Zhang [7]; Hsu, [8]; Miguel et al. [9]; Rahal $[10,11]$ and Vecchio [12,13]), have been regarded as major contributions in this area of research. This proposed approach admits that the cracking of a panel can occur by plasticization of the transverse and longitudinal reinforcements and cracking of the concrete before plasticization of the reinforcements.

Kachi et al. [14] continue the work of Grelat [15] and Nait-Rabah [16], showed in their model that the stress in concrete in the transverse direction is a compressive stress; they studied each section subjected to the bending moment, the normal force and the shear force in nonlinear elasticity in the case of the reinforced and prestressed concrete beams. The developed program has been validated on several reinforced and prestressed concrete beams which have been the subject of experimental tests.

Jeong et al. [17] propose a method to improve the nonlinear stress-strain analysis process of a reinforced concrete panel subjected to pure shear. Through this study, a comparison was made against the experimental data obtained by Hsu et al. [7], where it was found that the shear history was accurately estimated in the result of the analysis. Filho et al. [18] propose a softened truss model with variable angle (refined RA-STM) to model the behavior of reinforced concrete structural membranes under pure shear. They found that the general characteristics of the reinforced concrete (RC) panels under shear are well captured by the refined RASTM, namely for the ultimate state, as well as the need to refine the model for low load conditions. The RA-STM has been refined in several works (Bernardo et al. [19-21], Bernardo et al. [22]), in order to improve the numerical efficiency as well as provide good stability of the calculation procedure of membrane elements in reinforced concrete (RC) and prestressed concrete (PC). The refined model equations are reformulated using an optimization algorithm and an appropriate stress-strain relationship for tensile concrete is implemented. On the other hand, in the works (Bernardo et al. [23], Silva [24]), the contribution of tensile stresses in concrete has been neglected in the efficient RA-STM procedure. Through their comparison, it was shown only a good agreement for ultimate stage, namely for resistance, which is not the case for low loading stages. Bernardo and Sadieh [25] used the efficient RA-STM monotonic procedure in order to be able to predict the envelope curves $t 45^{\circ}-\mathrm{g} 45^{\circ}$ of reinforced concrete (RC) panels under cyclic shear loading. From the results obtained, they found that the efficient RA-STM procedure is a reliable model for predicting some important characteristics of the response of reinforced concrete (RC) panels studied under cyclic shear.

Also, in order to take into account, the uncertainties related to the physical phenomena that can be created during the sizing of structures, it is necessary to resort to probabilistic methods allowing the sizing of these structures to be optimized. The resulting research which has greatly improved our understanding of estimating the impact of the various uncertainties that can be created during the design of a structure, making it possible to evaluate their responses to uncertain variables, are summarized below. Freudenthal [26] first effectively investigated the possibility of using statistical techniques to quantify the safety of structural components which is based on the allowable stress method. Then several basic works of Cornell [27], Hasofer and Lind [28], found an ever increasing use in different fields of engineering. Mohamed and Lemaire [29] were interested in the coupling of mechanical analysis to reliability analysis to determine the probability of failure of marine platform structures. They opted for a materials model adopting linear sections, and an element's model admitting unloading situations. They proposed a reliability-model based on the concept of safety margins. The validation of their model was tested on examples of flat tubes and space gantries. State of the art reliability methods are briefly discussed by Rackwitz [30]. Benyahi et al. [31] proposed an analytical model making it possible to take account the mechanical nonlinearity in the nonlinear elasticity calculation of spatial trusses structures. The proposed mechanical model has been validated on several elements of three-dimensional metal trusses structures. Then, a reliability model was also used in order to estimate the reliability of this mechanical model, while proposing a method for estimating the distribution laws of the different random variables used in the mechanical model, by a response surface coupling technique between the two models. Some applications of reliability analysis for reinforced concrete structures have been reported by (Schlune et al. [32], Allaix et al. [33], El Ghoulbzouri et al. [34]; Olmati et al. [35]; Słowik et al. [36]), and prestressed concrete structures by (Rakoczy and Nowak [37], Hadidi et al. [38]). The combination of nonlinear analysis 
with reliability methods for the assessment of the reliability index has been used (Robuschi et al. [39], Slobbe et al. [40], Grubišić et al. [41]).

This paper aims to develop numerical models making it possible to represent as faithfully as possible the physical phenomena studied, and that by the use of an efficient theoretical model for the analysis of the sections behavior in the shear loading in the case of the reinforced and/or prestressed concrete beams. This calculation procedure should allow the analysis of different section shapes, and take into account the real materials behavior. In fact, given the complexity of the mechanical model studied, errors can occur because of a lack of information on the various design parameters. It is for this reason, that an evaluation of the reliability characteristics will be made by a procedure (FORM/SORM) in order to evaluate the probabilities of failure for the various transition zones of the limit state of the mechanical model solving the section's behavior in the shear loading in the case of the reinforced and/or prestressed concrete structural elements.

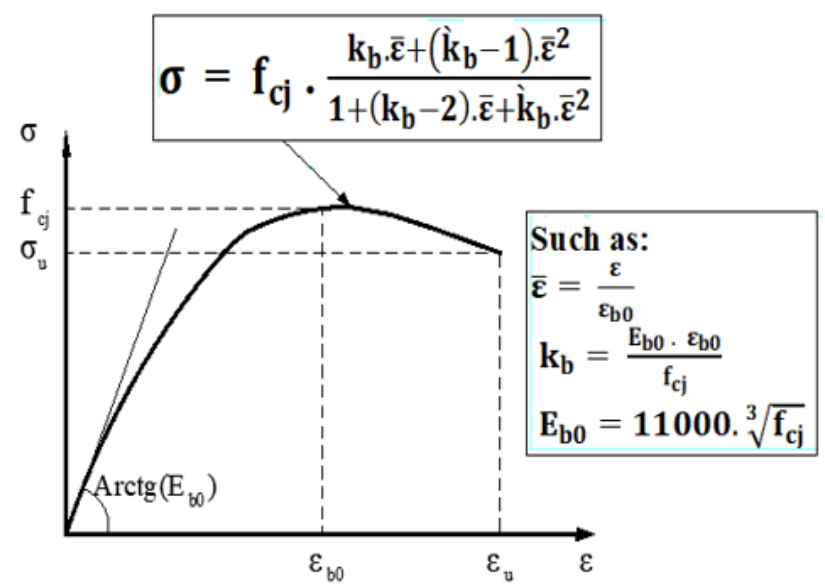

(a). Compression in principal compressive direction with Sargin [42]

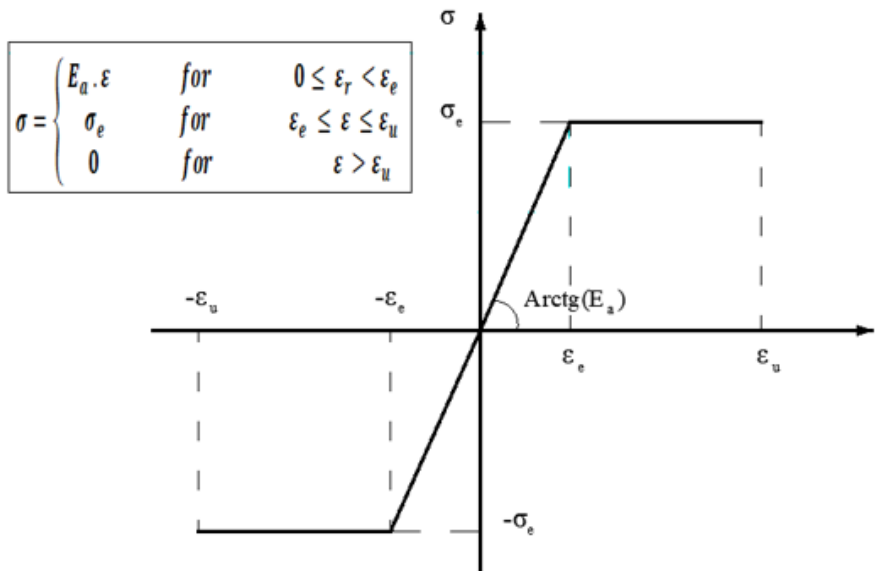

(b). Concrete in principal tensile direction with Grelat [15].

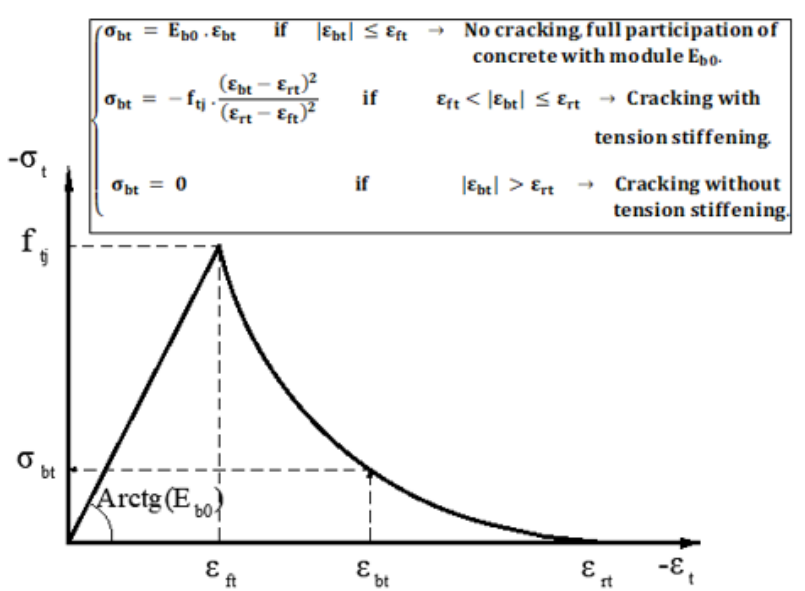

(b). Concrete in principal tensile direction with Grelat [15]

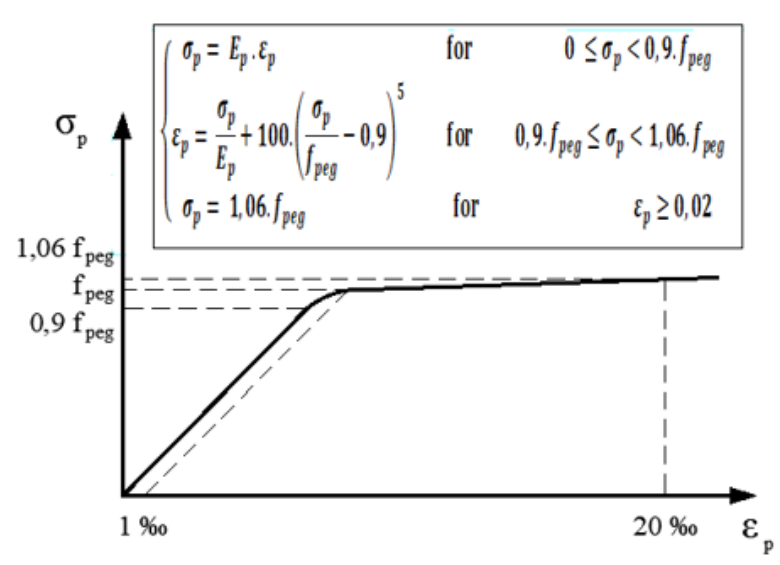

(d). Prestressing cable with BPEL99 [44]

Figure 1: Constitutive relations used in analysis procedure.

\section{STRESS-STRAIN RELATIONSHIPS USED IN ANALYSIS PROCEDURE}

I

$\mathrm{n}$ nonlinear elasticity, the stresses are related to the strains by the following relation:

$$
\sigma=\varphi(\varepsilon)
$$


The compressive concrete stresses are described by Sargin [42] law, the average tensile stress located between two cracks is described by the relation of Grelat [15], the stress of the reinforcement is described by the perfect elastoplastic constitutive law recommended by the BAEL99 rules [43], and the behavior of prestressing reinforcements is represented by the law recommended by the BPEL99 rules [44] (Fig. 1).

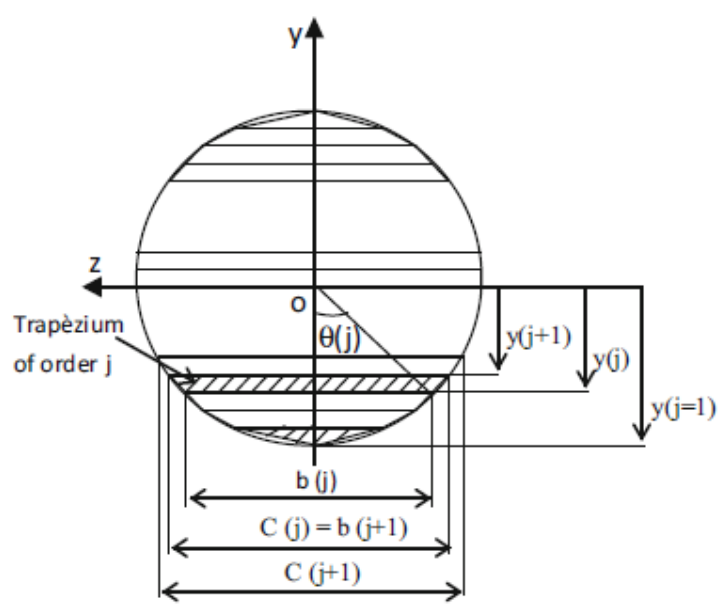

(a). Cross section of concrete in trapezoidal tables
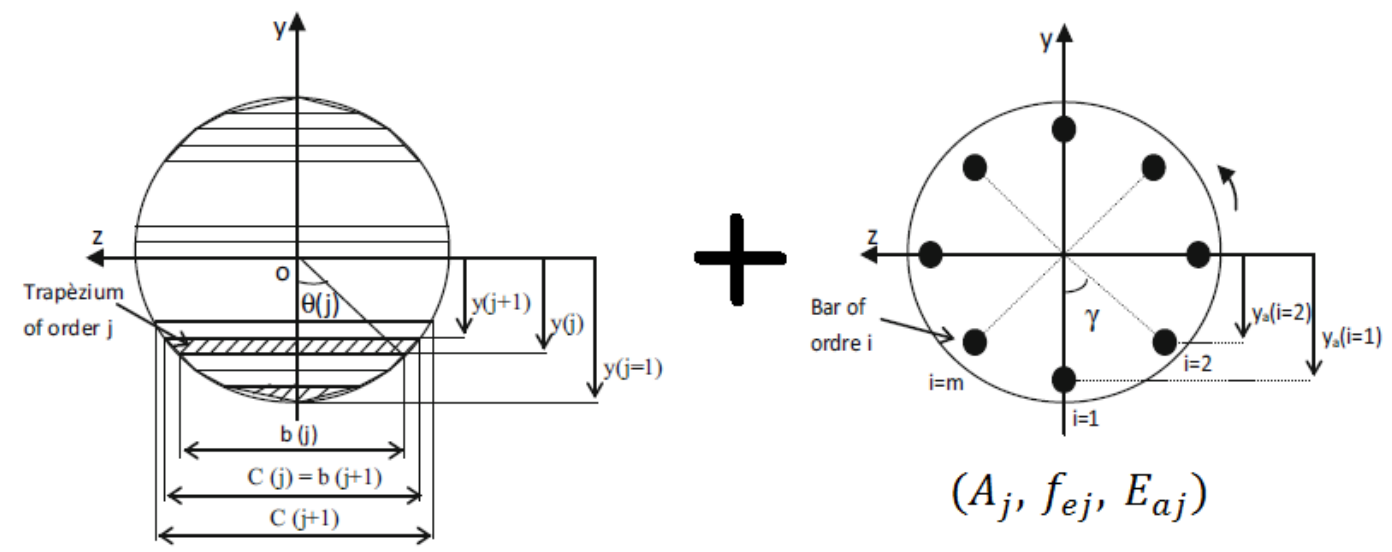

(b). Cross section of reinforced concrete
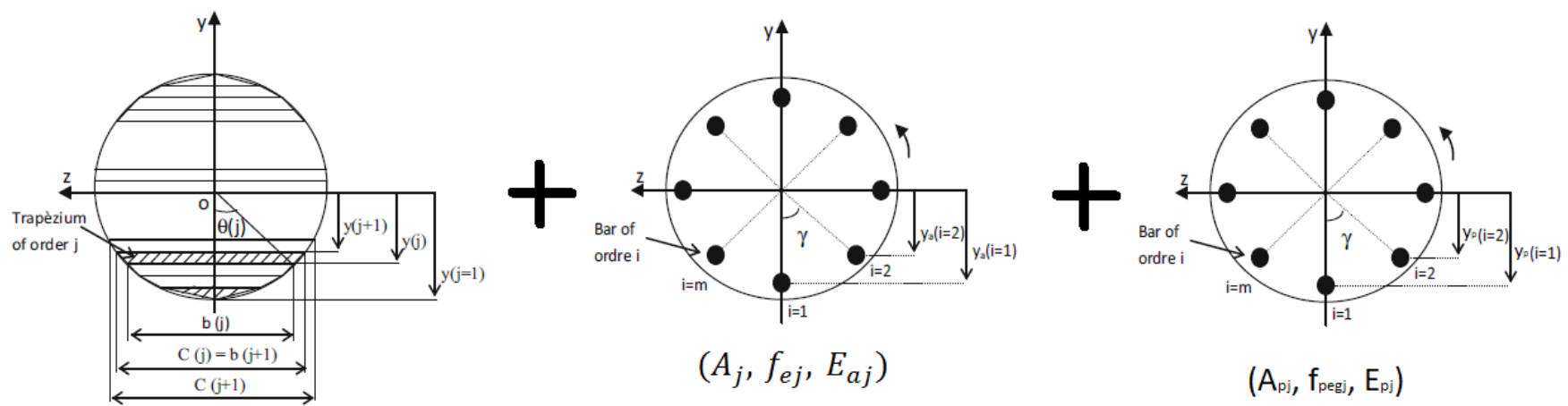

$$
\left(A_{j}, f_{e j}, E_{a j}\right)
$$

$\left(A_{p j}, f_{p e g j}, E_{p j}\right)$

(c). Cross section of reinforced and/or prestressed concrete

Figure 2: Discretization of a Layered Beam Cross Section. 


\section{DISCRETIZATION OF THE REINFORCED AND PRESTRESSED CONCRETE BEAM SECTIONS}

o better approximate the contour of a concrete section of any shape, the concrete section is considered as a succession of trapezoidal tables. Each table is defined by the width of its lower and upper base: $b_{j}, b_{j+1}$ as well as their ordinates $y_{j}, y_{j+1}$, with relatively to a reference axis passing through the sections gravity center, (Fig. 2.a). The integration process is numerical Simpson's method according to the Ref (Atkinson [45]), the trapeze width expression related to its ordinate $y$, is:

$$
b(y)=b_{j}+\left(b_{j+1}-b_{j}\right) \cdot\left(y-y_{j}\right) /\left(y_{j+1}-y_{j}\right)
$$

The section of each reinforcement is concentrated in its gravity center. The reinforcements are therefore defined as a succession of reinforcing beds, (Fig. 2. b). Each bed is defined by its ordinate $y_{a i}$ and by the total area of the reinforcement located at this level $A_{a i}$. The reinforcements prestressing are defined by their eccentricities $e_{p k}$ and their area $A_{p k}$ (Fig. 2. c).

On tensioning, the prestress practice on the concrete section an compressive force equal and opposite to the tensile force in the cable. This force is applied along the tangent to the mean line of the cable at the point where it crosses the section. The global strains in the concrete result from the external stresses and the actions of the prestressing reinforcement. From this state, it is considered that the prestressing cables become perfectly integral with the concrete, and they have a predeformation comparatively to the concrete section.

\section{CALCULATION PROCEDURE FOR A CROSS SECTION IN REINFORCED AND/OR PRESTRESSED CONCRETE}

7 he study of a cracked element subjected to the shear force consists on separately analyzing the materials constituting this element (concrete, steel). To solve the problem, it will be used the equilibrium equations, the compatibility equations and the constitutive laws of the different materials [14].

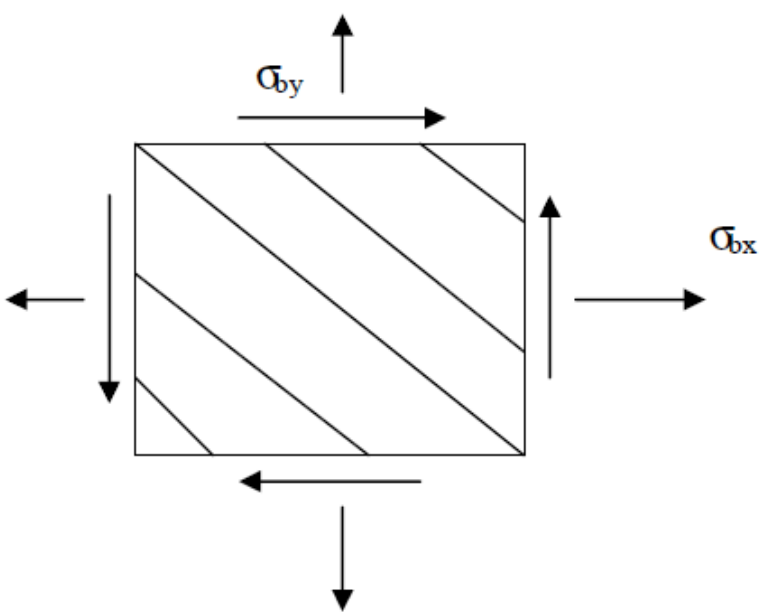

a) Average stresses

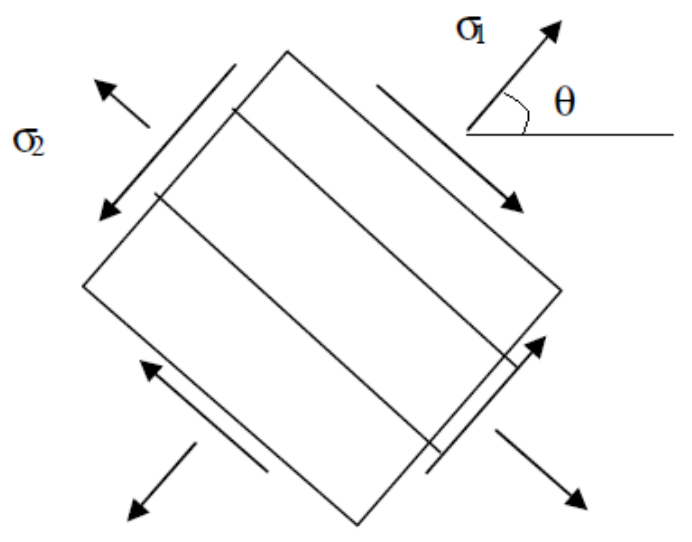

b) Main stresses

Figure 3: Average concrete stresses.

The longitudinal strain $\epsilon_{x}$ is a linear function of the $y$ ordinate, responding to the cross-section Navier-Bernoulli hypothesis and expressed as follows: 


$$
\epsilon_{x}(y)=\delta u+\delta w \cdot y
$$

On the assumption of an equivalent continuous medium for the concrete alone allowing to balance the shear stresses $\tau_{x}$ and $\tau_{y}$. The equilibrium equations linked the concrete stresses are:

$$
\begin{aligned}
& \sigma_{b x}=\sigma_{b 1} \sin ^{2} \theta_{b}+\sigma_{b 2} \cos ^{2} \theta_{b} \\
& \sigma_{b y}=\sigma_{b 1} \cos ^{2} \theta_{b}+\sigma_{b 2} \sin ^{2} \theta_{b} \\
& \tau_{b}=\tau=\left(\sigma_{b 1}-\sigma_{b 2}\right) \sin \theta_{b} \cos \theta_{b}
\end{aligned}
$$

We make the assumption of the coincidence of the principal directions of the concrete stresses with that of the average strains:

$$
\theta_{b}=\theta
$$

We assume that the strains of the concrete in the principal directions $\epsilon_{b 1}$ and $\epsilon_{b 2}$, which are related to the principal stresses $\sigma_{b 1}$ and $\sigma_{b 2}$, are equal to the average principal strains of the equivalent medium:

$$
\begin{aligned}
& \epsilon_{b 1}=\epsilon_{1} \\
& \epsilon_{b 2}=\epsilon_{2}
\end{aligned}
$$

While considering that the main direction (1) is perpendicular to the cracks. And the main direction (2) where the compressed connecting rods are parallel to the cracks (Fig. 3), and where we have a continuity of the concrete. The state of stress in concrete and steel is as follows, (see Fig. 4).

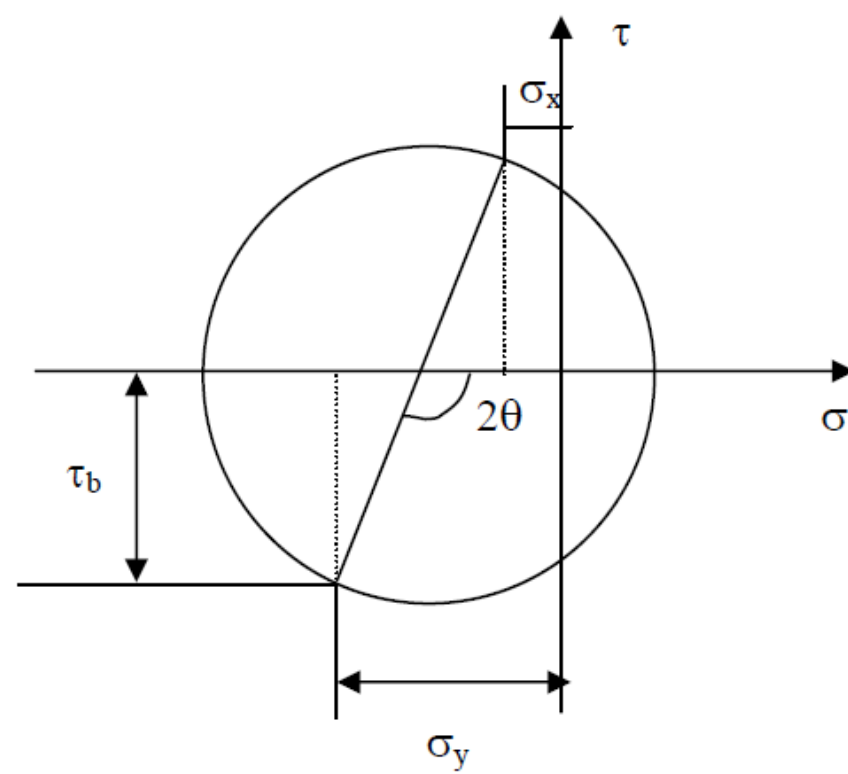

a) Concrete

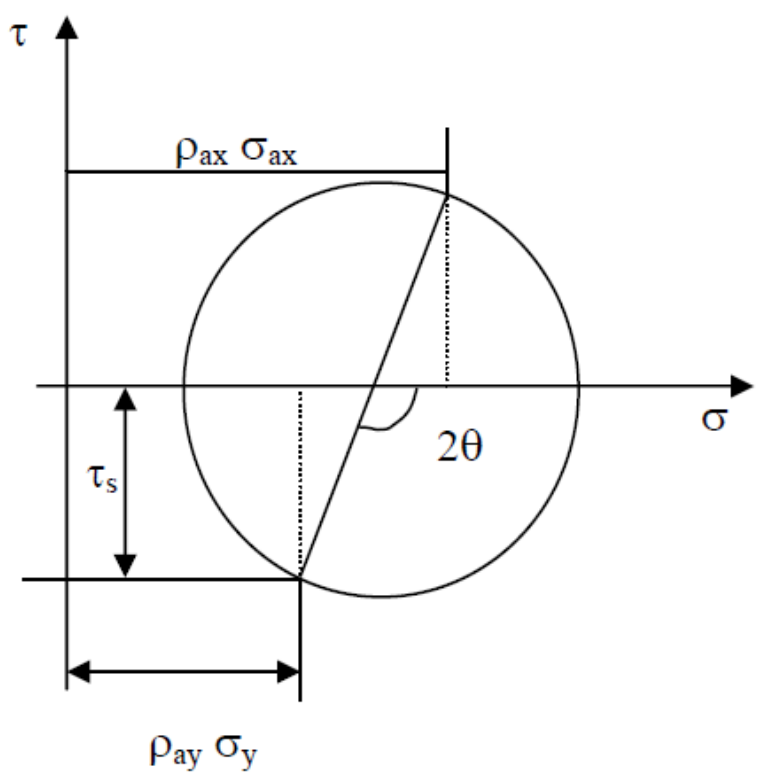

b) Steel

Figure 4: Mohr's circle for average stresses.

The general relations between the concretes main strains are thus: 


$$
\begin{aligned}
& \epsilon_{x}=\epsilon_{1} \sin ^{2} \theta+\epsilon_{2} \cos ^{2} \theta \\
& \epsilon_{y}=\epsilon_{1} \cos ^{2} \theta+\epsilon_{2} \sin ^{2} \theta \\
& \gamma=2\left(\epsilon_{1}-\epsilon\right) \sin \theta \cos \theta
\end{aligned}
$$

The local equilibrium of the concrete layers can be expressed as follows:

$$
\begin{aligned}
& \sigma_{x}=\rho_{x} \sigma_{a x}+\sigma_{b x} \\
& \sigma_{y}=\rho_{y} \sigma_{a y}+\sigma_{b y}=0
\end{aligned}
$$

The overall equilibrium of the sections is expressed by the equality of the external loads $\mathrm{N}, \mathrm{M}, \mathrm{V}$ and the resultants of the internal loads $N_{\text {int }}, M_{\text {int }}, V_{\text {int }}$, it is expressed by the following relation:

$$
\begin{aligned}
& N_{\text {int }}=\sum_{i} \mathrm{~A}_{\mathrm{xi}} \sigma_{\mathrm{axi}}+\sum_{i} \mathrm{~b}_{\mathrm{i}} \mathrm{h}_{\mathrm{i}} \sigma_{\mathrm{bxi}} \\
& M_{\text {int }}=\sum_{i} \mathrm{~A}_{\mathrm{xi}} \sigma_{\text {axi }} \mathrm{y}_{\mathrm{ai}}+\sum_{i} \mathrm{~b}_{\mathrm{i}} \mathrm{h}_{\mathrm{i}} \sigma_{\mathrm{bxi}} \mathrm{y}_{\mathrm{i}}
\end{aligned}
$$

For the shear force, only the shear stresses in the concrete are involved:

$$
V_{\text {int }}=\sum_{i} \mathrm{~b}_{\mathrm{i}} \mathrm{h}_{\mathrm{i}} \tau_{\mathrm{bi}}
$$

The principal stress $\sigma_{b 2}$ is a function of the two principal strains $\epsilon_{1}$ and $\epsilon_{2}$ :

$$
\sigma_{b 2}=E_{b 2}\left(\epsilon_{2}, \epsilon_{1}\right) \cdot \epsilon_{2}
$$

The stress-strain law of concrete in traction is linear before concrete cracking. Beyond that, the tensile stress decreases with increasing mean tensile strain, which includes the effect of crack opening (Fig. 5).

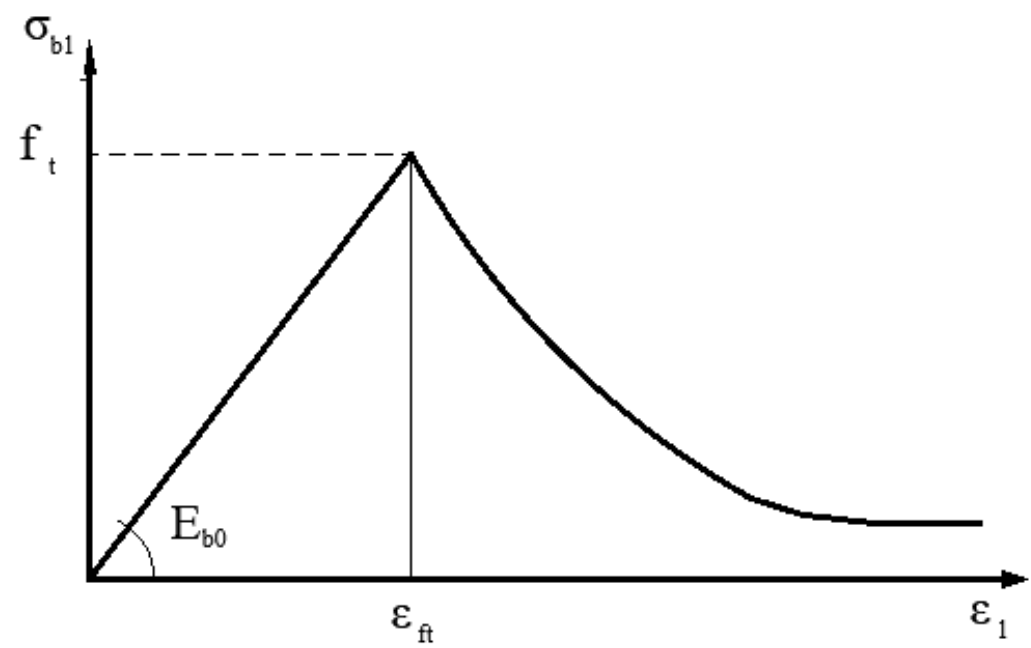

Figure 5: Behavior of tensile concrete according to Belarbi and Hsu [46]. 
Before concrete cracking:

$$
\left|\varepsilon_{1}\right| \leq \varepsilon_{\mathrm{ft}} \quad: \quad \sigma_{\mathrm{b} 1}=\mathrm{E}_{\mathrm{b} 0} \cdot \varepsilon_{1}
$$

To describe the decreasing branch, after cracking, which reflects the influence of the concrete loaded between the cracks on the average strain, we adopt the relation proposed by Belarbi and Hsu [46]:

$$
\sigma_{b 1}=\mathrm{f}_{\mathrm{t}}\left(\frac{\varepsilon_{\mathrm{ft}}}{\varepsilon_{1}}\right)^{0,4}
$$

where: $\quad \epsilon_{f t}=\frac{f_{t}}{E_{b 0}}$

The behaviors of reinforcement and the prestressing reinforcement are characterized by the types of relations admitted by the rules BAEL99 [43] and BPEL99 [44]:

- Longitudinal reinforcement

$$
\sigma_{a x}=E_{a}\left(\epsilon_{x}\right) \cdot \epsilon_{x}
$$

- Transverse reinforcement

$$
\sigma_{a y}=E_{a t}\left(\epsilon_{y}\right) \cdot \epsilon_{y}
$$

- Prestressing reinforcement

$$
\sigma_{p x}=E_{a p}\left(\epsilon_{x}\right) \cdot \epsilon_{x}
$$

The shear stresses are then deduced from the equilibrium of the layers between the design section under the loading state $(\mathrm{N}, \mathrm{M}, \mathrm{V})$ and the neighboring section subjected to the forces $\left(N_{1}, M_{1}, V_{1}\right)$ which are expressed by:

$$
\begin{aligned}
& N_{1}=N \\
& M_{1}=M-V . d \\
& V_{1}=V
\end{aligned}
$$

The two sections are analyzed so as to satisfy in each of them the equilibrium equations. By applying the classical RDM method, we study the equilibrium of all the forces acting on a layer of order k shown in the figure (Fig. 6):

Section 2

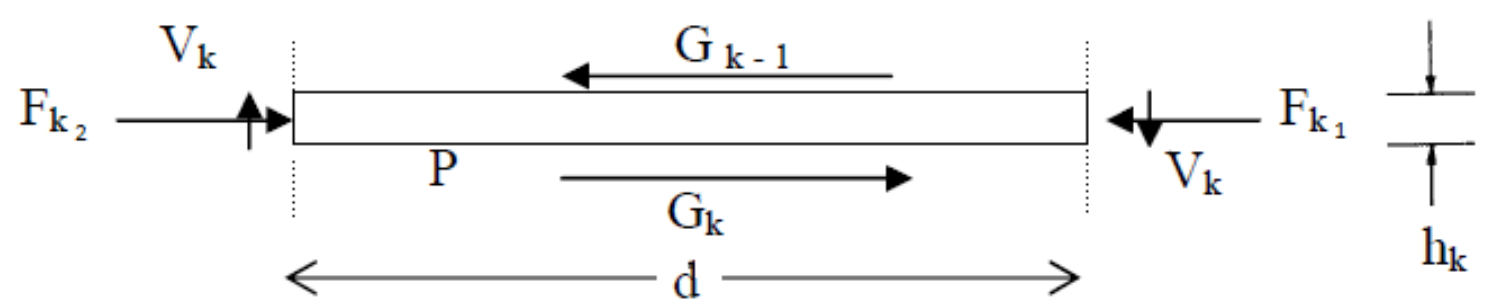

Figure 6: Forces acting on a concrete layer between two sections. 
The equilibrium of the section makes it possible to calculate the shear value $V_{k}$, by writing that the moment of the forces is zero at point $\mathrm{P}$ :

$$
V_{k}=\frac{\left(G_{k-1}+G_{k}\right)}{2} \frac{h_{k}}{d}
$$

The average value of the shear stress on the layer $\mathrm{k}$ is then given by:

$$
\tau_{\mathrm{k}}=\frac{\mathrm{V}_{\mathrm{k}}}{\mathrm{b}_{\mathrm{k}} \mathrm{h}_{\mathrm{k}}}=\frac{\left(\mathrm{G}_{\mathrm{k}-1}+\mathrm{G}_{\mathrm{k}}\right)}{2 \mathrm{~d} \mathrm{~b}_{\mathrm{k}}}
$$

The mean shear strain of the section $\gamma_{\text {moy }}$ is calculated from the theorem of virtual work expressing the equality of the external forces work $\Delta W_{e}$ and that of the internal forces $\Delta W_{i}: \quad \Delta W_{e}=\sum_{1}^{m} \Delta \mathrm{w}_{\mathrm{i}}$

From where:

$$
\Delta \gamma_{\text {moy }}=\sum_{1}^{\mathrm{m}} \frac{\Delta \tau_{\mathrm{i}} \mathrm{b}_{\mathrm{i}} \mathrm{h}_{\mathrm{i}} \Delta \gamma_{\mathrm{i}}}{\Delta \mathrm{V}}
$$

For the resolution of the problem, we explain some quantities from the previous general equations. We take from Eqn. 10 :

$$
\varepsilon_{1}=\frac{\varepsilon_{x}}{\sin ^{2} \theta}-\frac{\varepsilon_{2}}{\operatorname{tg}^{2} \theta}
$$

We also rewrite the Eqn. 4, Eqn. 5 and Eqn. 6 between the concrete stresses in the following form (taking into account Eqn. 7):

$$
\begin{aligned}
& \sigma_{b x}=\sigma_{b 2}+\sigma_{b 1}-\sigma_{b y} \\
& \theta=\operatorname{tg}^{-1}\left(\frac{\sigma_{b 2}-\sigma_{b x}}{\sigma_{b 2}-\sigma_{b y}^{\prime}}\right)^{1 / 2} \\
& \sigma_{b 2}=\sigma_{b y}-\frac{\tau}{\operatorname{tg} \theta}
\end{aligned}
$$

The study of the equilibrium of a reinforced concrete layer, where $\epsilon_{x}$ and $\tau$ are known uses a system of equation. To solve it, we call on an iterative method.

For a given distribution of the longitudinal strains, we assume known the main strain $\epsilon_{2}$ and we look for the value of the angle $\theta$ which makes it possible to satisfy the conditions of compatibility and equilibrium of the layer. The tangential stresses $\tau(y)$ are calculated by the equilibrium of two neighboring sections (Eqn. 26). The complete resolution at the section level is described by the flowchart in Fig. 7.

\section{RELIABILITY CALCULATION PROCEDURE}

he concept of safety based on the concept of allowable stress was recognized insufficient because of the uncertainty of the loading parameters and the uncertainty of the structures mechanical properties. However, in recent years, a so-called semi-probabilistic theory ensures safety by introducing various partial coefficients taking 
into account the limit state considered. The use of reliability methods (FORM/SORM) consists in determining the reliability index $\beta$ and obtaining an approximation of the probability of failure [22].

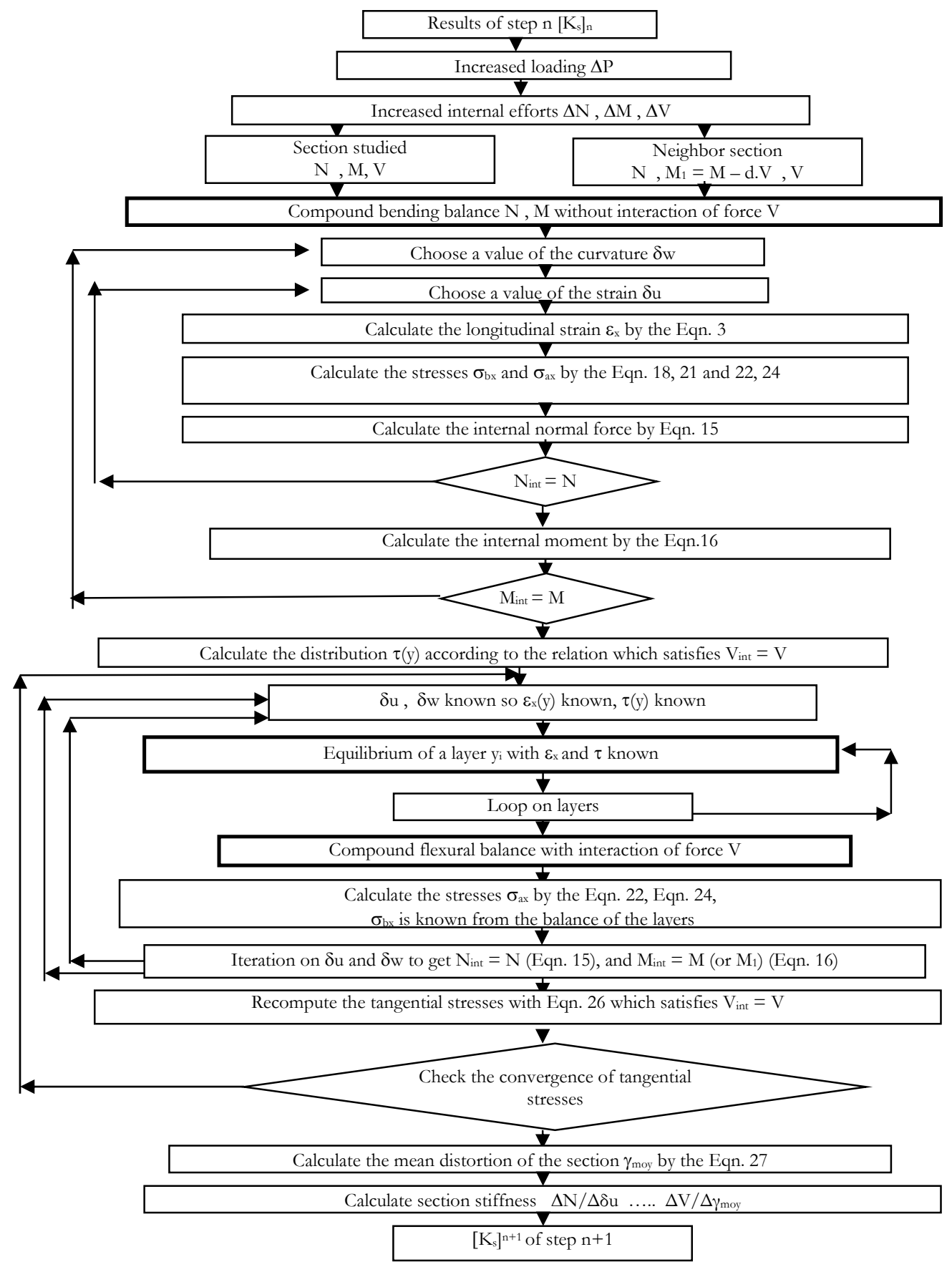

Figure 7: General flowchart of the study of a section [14].

The first step is to find the most probable point of failure $P^{*}$ in the space of standard variables. Then, the limit state function is approximated by its first order Taylor expansion (FORM) or second order (SORM), around the point of conception. 
In the space of physical variables $X$, the limit state function is denoted $G(X)$ and in the standard space, we denote it $H(u)$. The second-order Taylor series expansion of the limit state function $H(u)$ around the point $P^{(\mathrm{k})}$ is written as follows:

$$
H(u)=H\left(u^{(k)}\right)+\langle\nabla H(u)\rangle_{u^{(k)}}\left(\{u\}-\{u\}^{(k)}\right)+O\left(\{u\}-\{u\}^{(k)}\right)^{2}
$$

The search for the design point $U^{*}$ is a solution of the following optimization problem:

$$
\beta_{H L}=\min _{g\left\{x_{i}\left(u_{i}\right)\right\} \leq 0} \sqrt{\{u\}^{T}\{u\}}
$$

Under constraint $H(u) \leq 0$

The design point (or most probable point of failure) is the point on the limit state surface where the probability density of $U$ is maximum, it is also defined as the point on the limit state surface closest to the origin. In this study the constrained minimization problem will be solved, using the Hasofer-lind-Rackwitz-Fiessler algorithm which is an adaptation of a first order optimization algorithm to the design point search problem.

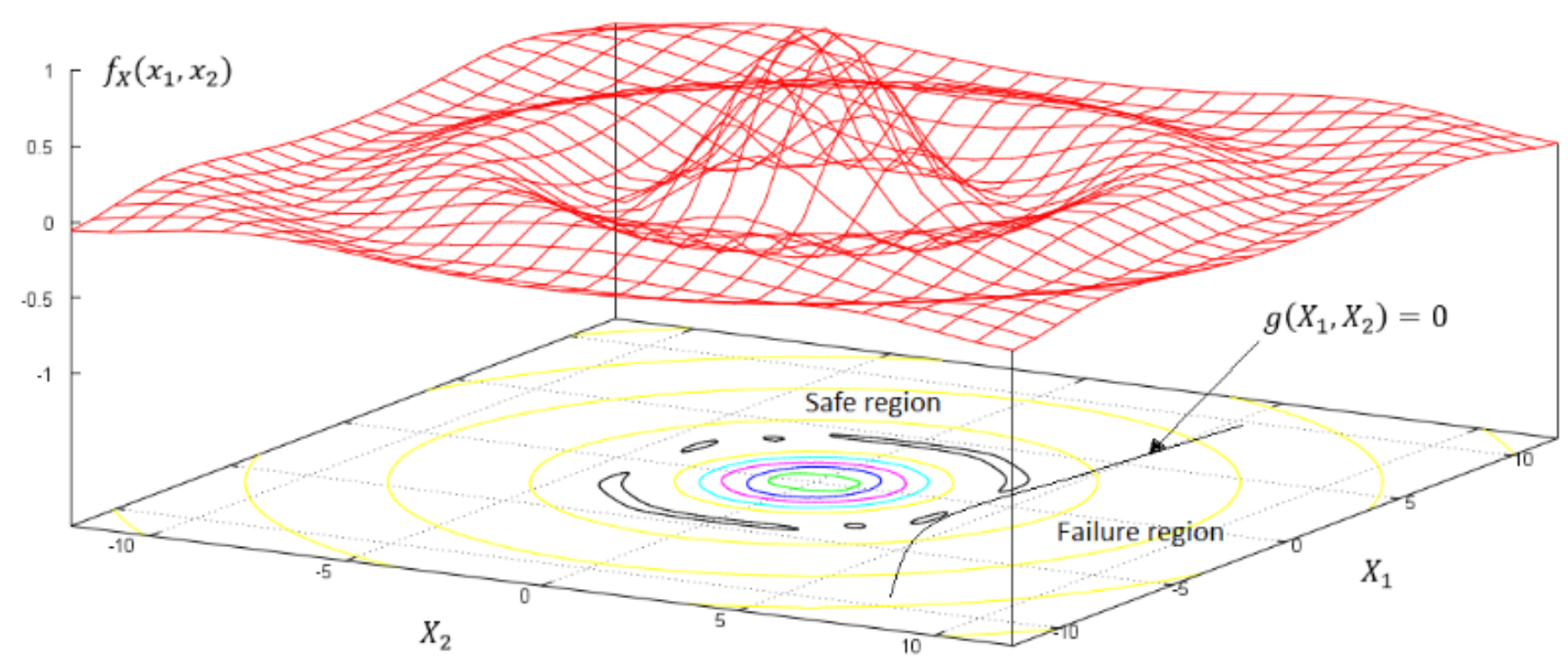

Figure 8: Safe and Unsafe Regions approach for computing Hasofer Lind Reliability Index.

The equation of the tangent hyper-plane to $H(u)$ at the point $P^{(\mathrm{k}+1)}$ is defined as follows:

$$
H\left(u^{(k+1)}\right)=H\left(u^{(k)}\right)+\langle\nabla H(u)\rangle_{u^{(k)}}\left(\{u\}^{(k+1)}-\{u\}^{(k)}\right)=0
$$

By dividing the equation by the norm $\|\nabla H(u)\|_{u^{(k)}}$ and by introducing the direction cosines of $H$ at the point $P^{(\mathrm{k})}$ we obtain:

$$
\frac{H\left(u^{(\mathrm{k})}\right)}{\|\nabla H(u)\|_{u^{(k)}}}+\langle\alpha\rangle^{(k)}\left(\{u\}^{(k+1)}-\{u\}^{(k)}\right)=0
$$


It results:

$$
\langle u\rangle^{(k+1)}\{\alpha\}^{(k)}=\langle u\rangle^{(k)}\{\alpha\}^{(k)}-\frac{H\left(u^{(\mathrm{k})}\right)}{\|\nabla H(u)\|_{u^{(k)}}}
$$

with $\alpha^{(k)}=\frac{\nabla H\left(u^{(\mathrm{k})}\right)}{\|\nabla H(u)\|_{u^{(k)}}}$ the vector of direction cosines (or the vector of the normalized gradient) of $H$ at the point $P^{(\mathrm{k})}$. Ultimately when $k \rightarrow \infty, d\left(u^{(k)}\right)=\beta$ and $\{u\}=-\beta\{\alpha\}$ if the algorithm is convergent at iteration $(k)$, let us set:

$$
\{u\}^{(k+1)}=-\beta^{(k)} \cdot\{\alpha\}^{(k)} \Rightarrow \beta^{(k)}=-\langle u\rangle^{(k+1)} \cdot\{\alpha\}^{(k)}
$$

Solving the problem gives a value of $\beta$ which corresponds to the reliability index known as of Hasofer and Lind. Which leads to the iterative relation giving the reliability index:

$$
\beta^{(k)}=-\langle u\rangle^{(k)}\{\alpha\}^{(k)}+\frac{H\left(u^{(\mathrm{k})}\right)}{\|\nabla H(u)\|_{u^{(k)}}}
$$

The reliability index search algorithm stops when the standard $\left\|\{u\}^{(k+1)}-\{u\}^{(k)}\right\| \leq t$.

where

$t:$ the fixed tolerance.

and $\{u\}^{(k+1)}$, is deduced by replacing Eqn. 38 in Eqn. 37 by:

$$
\{u\}^{(k+1)}=\left(\langle u\rangle^{(k)}\{\alpha\}^{(k)}\right)\{\alpha\}^{(k)}-\frac{H\left(u^{(\mathrm{k})}\right)}{\|\nabla H(u)\|_{u^{(k)}}}\{\alpha\}^{(k)}
$$

In standardized space, the approximate FORM/SORM (First/Second Order Reliability Method) consists of substituting for the failure surface a hyperplane tangent to this surface at the design point. An estimate of the probability of failure is then obtained by:

$$
P_{f}=\frac{1}{\sqrt{2 \pi}} \int_{-\infty}^{-\beta_{C}} \exp \left(-\frac{u^{2}}{2}\right) d u=\Phi\left(-\beta_{C}\right)
$$

In this present study the Hasofer-Lind index will be used because it allows to solve the problem caused by the noninvariance. To overcome this problem, Hasofer and Lind proposed not to place themselves in the space of physical variables, but to perform a change of variable, towards a new space of statistically independent Gaussian variables with zero means and unit standard deviations:

$X_{i} \rightarrow U_{i}$ Gaussian vector $\mathcal{N}(0,1)$

$$
\mu_{U_{i}}=0, \sigma_{U_{i}}=1, \rho_{i j}=0, \forall i, \forall j
$$

In the case of independent Gaussian variables, the transformation of the physical space into the standard normal space is iso-probabilistic: 


$$
x_{i} \quad \stackrel{T}{\rightarrow} \quad u_{i}=\frac{x_{i}-\mu_{x_{i}}}{\sigma_{x_{i}}}
$$

For uncorrelated variables of any law, the principle of the transformation consists in writing the equality of the functions distribution:

$$
\Phi(u)=F_{X}(x) \Rightarrow x \rightarrow u=\Phi^{-1}\left(F_{X}(x)\right)
$$

The Hasofer-Lind-Rackwitz-Fiessler (HL-RF) algorithm is summarized by the following steps:

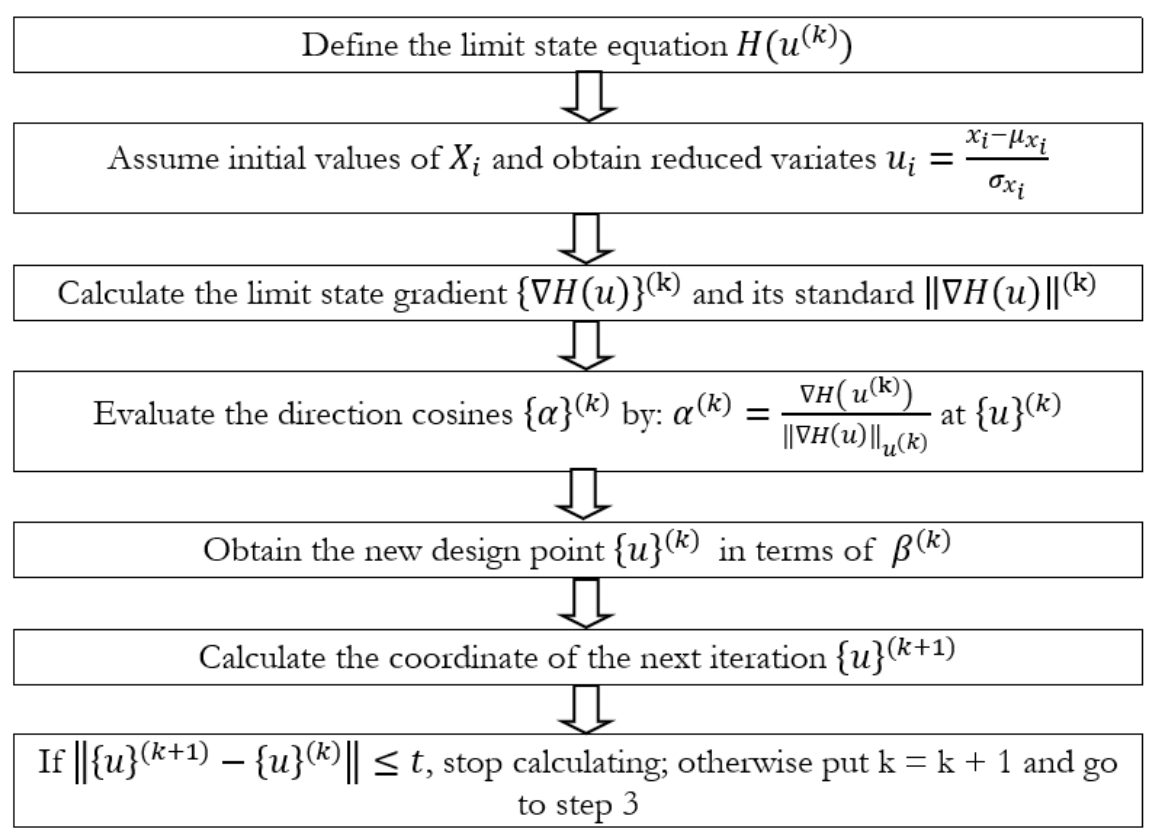

Figure 9: Algorithm to compute $\beta_{H L}$.

The flowchart of the mechano-reliability coupling by analytical response surface is described below:

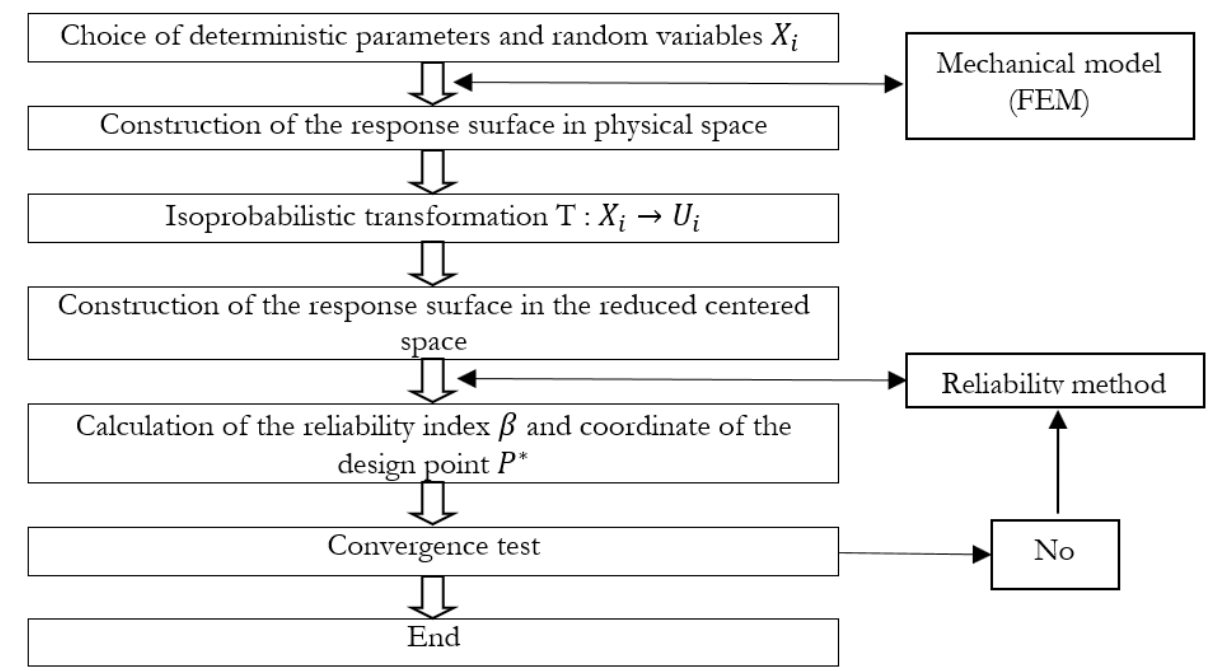

Figure 10: Flowchart of the mechano-reliability coupling by response surface. 


\section{RESULTS AND VALIDATION}

he mechanical shear-bending model of beam sections was used to simulate the behavior of several beams tested by various researchers at the University of Toronto (Vecchio and Collins [2,3]). The beams have a solid or hollow rectangular cross section of reinforced and/or prestressed concrete. The geometric characteristics and the properties of the different materials are given in the Tab. 1.

\begin{tabular}{|c|c|c|c|c|c|c|c|c|c|c|c|c|}
\hline \multirow{2}{*}{$\begin{array}{l}\text { REFEREN } \\
\text { CE BEAM }\end{array}$} & \multicolumn{2}{|c|}{ DIMENSIONS } & \multicolumn{2}{|c|}{ CONCRETE } & \multicolumn{3}{|c|}{$\begin{array}{c}\text { TRANSVERSE } \\
\text { REINFORCEMENT }\end{array}$} & \multicolumn{2}{|c|}{$\begin{array}{l}\text { LONGITUDIN } \\
\text { AL } \\
\text { REINFORCEM } \\
\text { ENT }\end{array}$} & \multicolumn{3}{|c|}{$\begin{array}{c}\text { PRESTRESSING } \\
\text { REINFORCEMENT } \\
\mathrm{S}\end{array}$} \\
\hline & $\begin{array}{l}\text { EXT } \\
(\mathrm{mm})\end{array}$ & $\begin{array}{l}\text { INT } \\
(\mathrm{mm})\end{array}$ & $\begin{array}{c}f_{c} \\
(\mathrm{MPa})\end{array}$ & $\begin{array}{c}\varepsilon_{\mathrm{b} 0} \\
10^{-3}\end{array}$ & $\begin{array}{l}\text { Barres } \phi \\
\quad(\mathrm{m})\end{array}$ & $\begin{array}{c}\mathrm{s}_{\mathrm{t}} \\
(\mathrm{mm})\end{array}$ & $\begin{array}{c}\mathrm{f}_{\mathrm{e}} \\
(\mathrm{MPa})\end{array}$ & $\begin{array}{l}\text { Nb.x } \\
\phi(\mathrm{mm})\end{array}$ & $\begin{array}{c}\mathrm{f}_{\mathrm{e}} \\
(\mathrm{MPa})\end{array}$ & $\begin{array}{c}\mathrm{A}_{\mathrm{p}} \\
\left(\mathrm{mm}^{2}\right)\end{array}$ & $\begin{array}{c}\mathrm{f}_{\mathrm{pe}} \\
(\mathrm{MPa})\end{array}$ & $\begin{array}{l}\Delta \varepsilon_{\mathrm{p}} \\
10^{-3}\end{array}$ \\
\hline SA3 & $305 \times 610$ & $152 \times 406$ & 40.0 & 2.8 & 9.5 & 72 & 373 & $\begin{array}{l}12 \times 29 \\
4 \times 22\end{array}$ & $\begin{array}{l}345 \\
462\end{array}$ & - & - & - \\
\hline SA4 & $305 \times 610$ & $152 \times 406$ & 40.0 & 2.8 & 9.5 & 72 & 373 & $\begin{array}{l}12 \times 29 \\
4 \times 22\end{array}$ & $\begin{array}{l}345 \\
462\end{array}$ & - & - & - \\
\hline SK1 & $305 \times 610$ & - & 26.9 & 2.25 & 9.5 & 100 & 400 & $8 \times 25$ & 442 & 1540 & 1450 & 4.82 \\
\hline SK2 & $305 \times 610$ & $121 \times 381$ & 26.9 & 2.25 & 9.5 & 100 & 400 & $8 \times 25$ & 442 & 1540 & 1450 & 4.82 \\
\hline SK3 & $305 \times 610$ & - & 28.2 & 2.2 & 9.5 & 100 & 400 & $8 \times 25$ & 442 & - & - & - \\
\hline SK4 & $305 \times 610$ & $121 \times 381$ & 28.2 & 2.2 & 9.5 & 100 & 400 & $16 \times 25$ & 442 & - & - & - \\
\hline SP0 & $305 \times 610$ & $152 \times 406$ & 25.0 & 2.3 & 9.5 & 150 & 373 & $16 \times 25$ & 421 & - & - & _ \\
\hline SP1 & $305 \times 610$ & $152 \times 406$ & 33.5 & 2.3 & 9.5 & 150 & 373 & $12 \times 22$ & 421 & 510 & 1450 & 4.21 \\
\hline SP2 & $305 \times 610$ & $152 \times 406$ & 32.0 & 2.0 & 9.5 & 150 & 373 & $12 \mathrm{x} 22$ & 421 & 1010 & 1450 & 4.11 \\
\hline SP3 & $305 \times 610$ & $152 \times 406$ & 32.2 & 2.0 & 9.5 & 150 & 373 & $12 x 22$ & 421 & 1520 & 1450 & 4.26 \\
\hline SM1 & $305 \times 610$ & $152 \times 406$ & 29.0 & 2.4 & 9.5 & 175 & 424 & $12 x 22$ & 452 & - & - & - \\
\hline CF1 & $305 \times 610$ & $152 \times 406$ & 38.6 & 3.0 & 9.5 & 150 & 367 & $6 \times 9.5$ & 367 & 930 & 1450 & 5.17 \\
\hline
\end{tabular}

Table 1: Properties of different beams Vecchio and Collins [2, 3].

The Figs. (11-15) from a comparative calculation results to the experiment results in the case of reinforced and prestressed concrete tested at Toronto university.

We can observe from the Figs. (11-15) that the results obtained from the numerical model compared to the experimental results make it possible to approach the real behavior of all the reinforced and/or prestressed concrete beams studied, as well before and after cracking of the concrete.

We notice an error made on the ultimate values of the load varying between $(0.28 \%$ and $8.94 \%)$ for reinforced concrete; and $(3.40 \%$ and $12.89 \%)$ for prestressed concrete beams. The distortion observed in the beams (SA3, SA4, SK2, SP0, SP1, SP3) shows an important value, especially when approaching the maximum load. However, there are no results measures other than the distortion $\gamma_{\text {moy }}$ to analyze the cause of the observed differences in some cases between calculation and testing.

We can also note, in the phase of the behavior before concrete cracking, that all the curves obtained display an elastic plateau approaching the experimental results, and that the numerical model fairly correctly predicts the evolution of the distortion $\gamma_{\text {moy }}$ with the shear force $\mathrm{V}$. On the other hand, in the behavior phase after cracking of the concrete and before plasticization of the steel, we notice a decrease in the shear rigidity of the reinforced and/or prestressed concrete beams studied, which increases the distortion until plasticization reinforcements. Beyond that, the distortion tends to increase significantly until failure. 


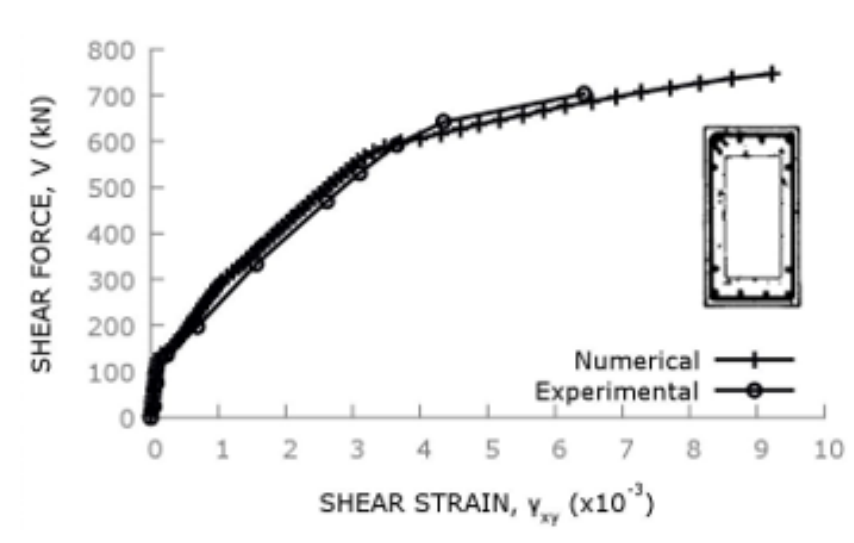

(a). Comparison of results beam $\mathrm{SA} 3$

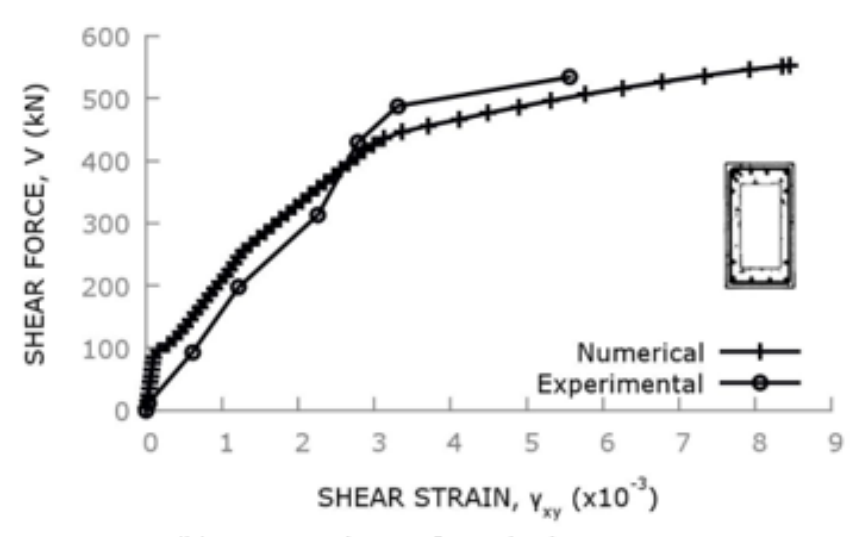

(b). Comparison of results beam SA4

Figure 11: Analysis of shear beam (SA).

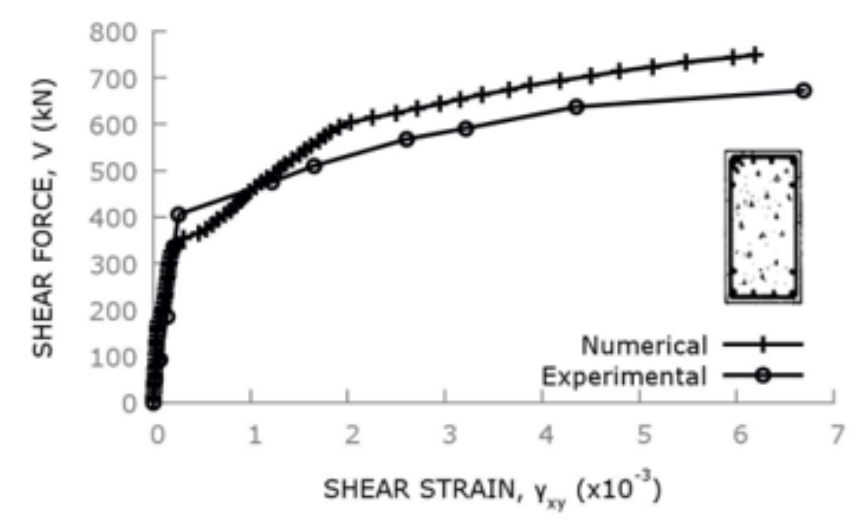

(a). Comparison of results beam SK1

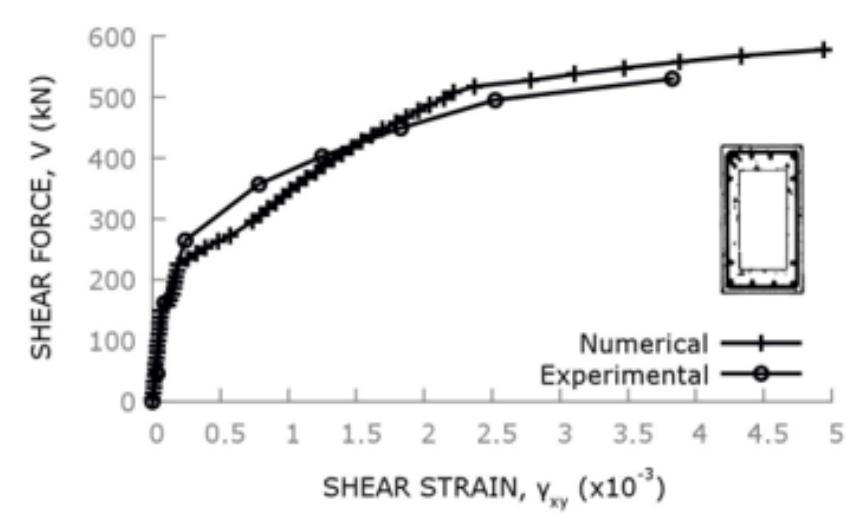

(b). Comparison of results beam $\mathrm{SK} 2$

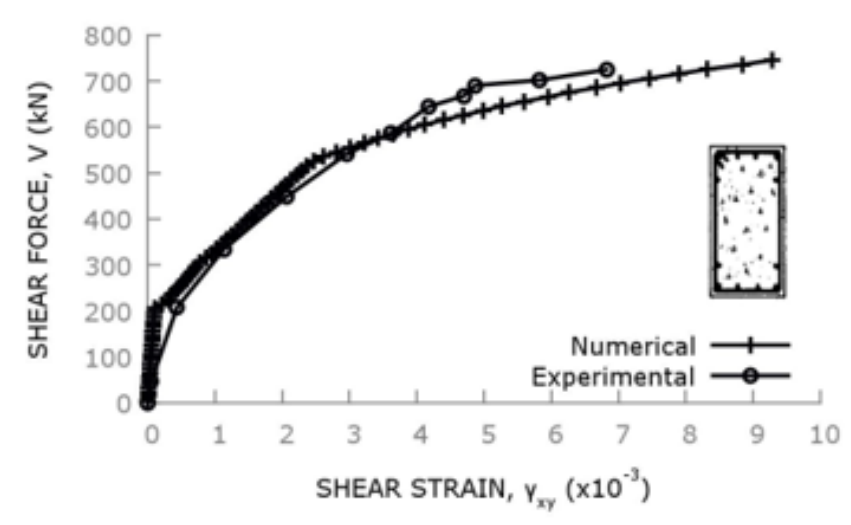

(c). Comparison of results beam SK3

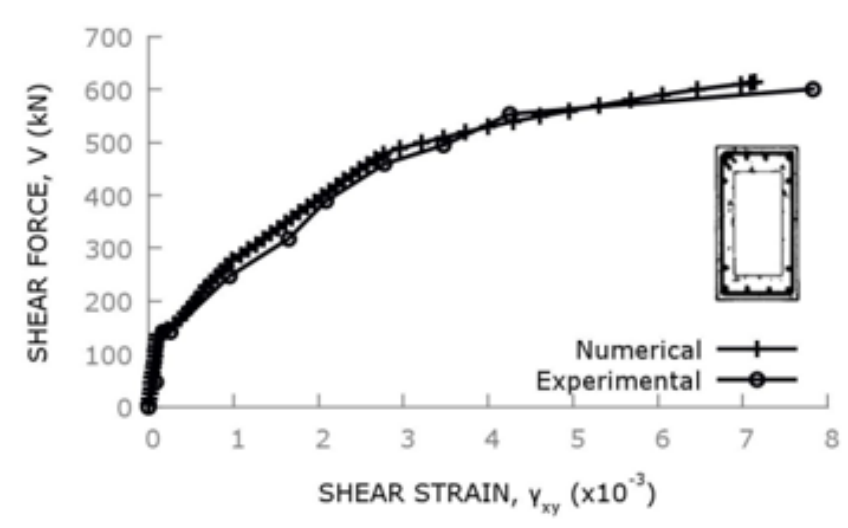

(d). Comparison of results beam SK4

Figure 12: Analysis of shear beam (SK). 


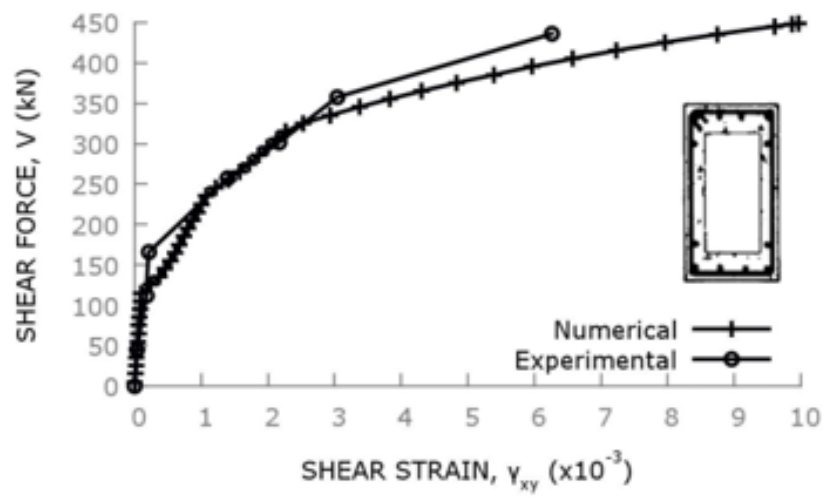

(a). Comparison of results beam SP0

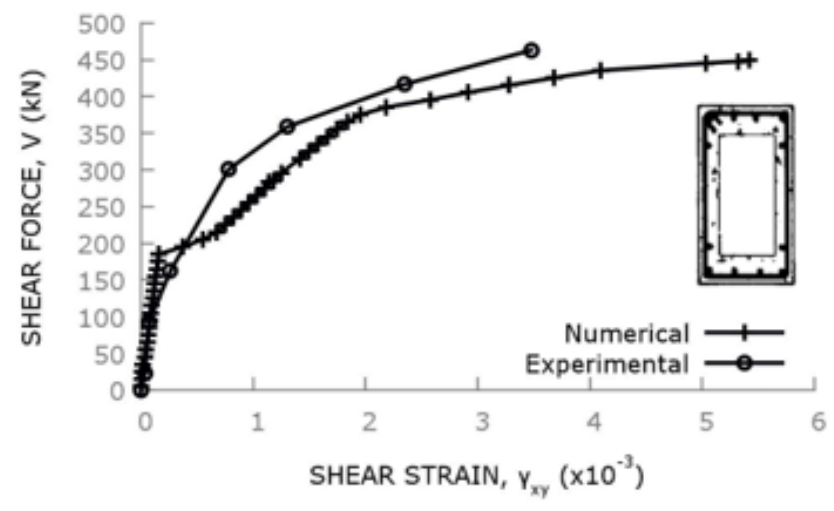

(b). Comparison of results beam SP1

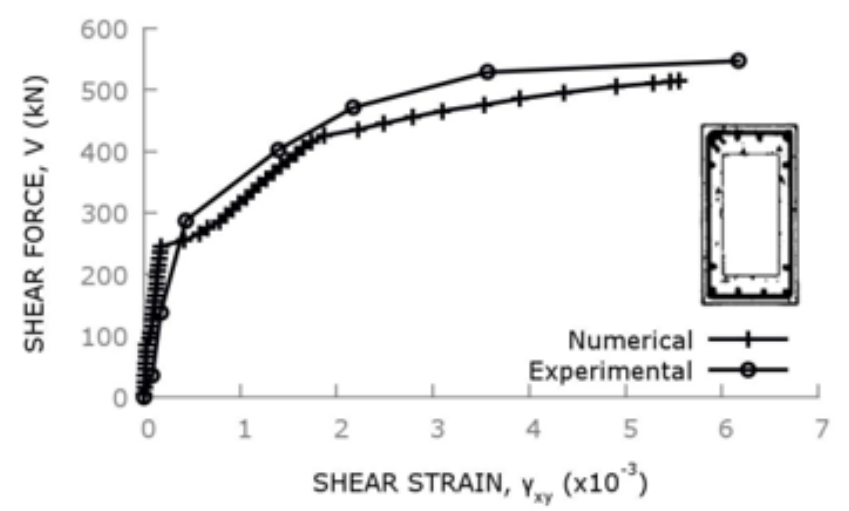

(c). Comparison of results beam SP2

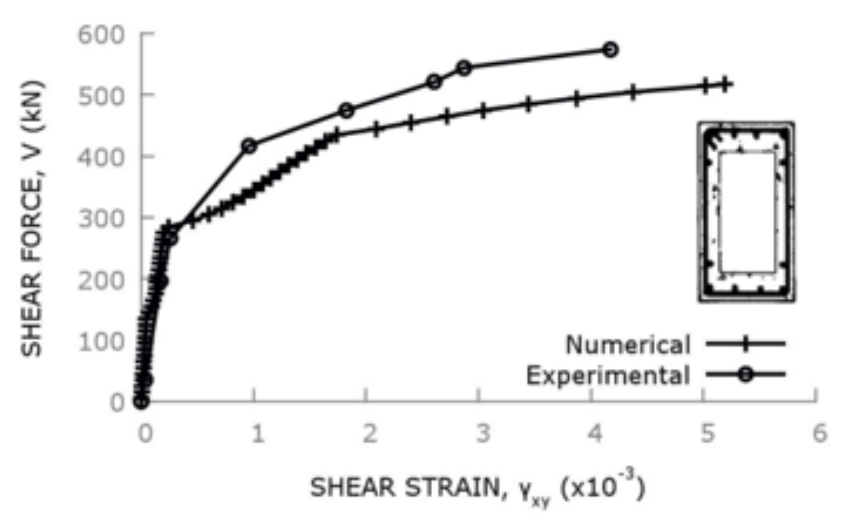

(d). Comparison of results beam SP3

Figure 13: Analysis of shear beam (SP).

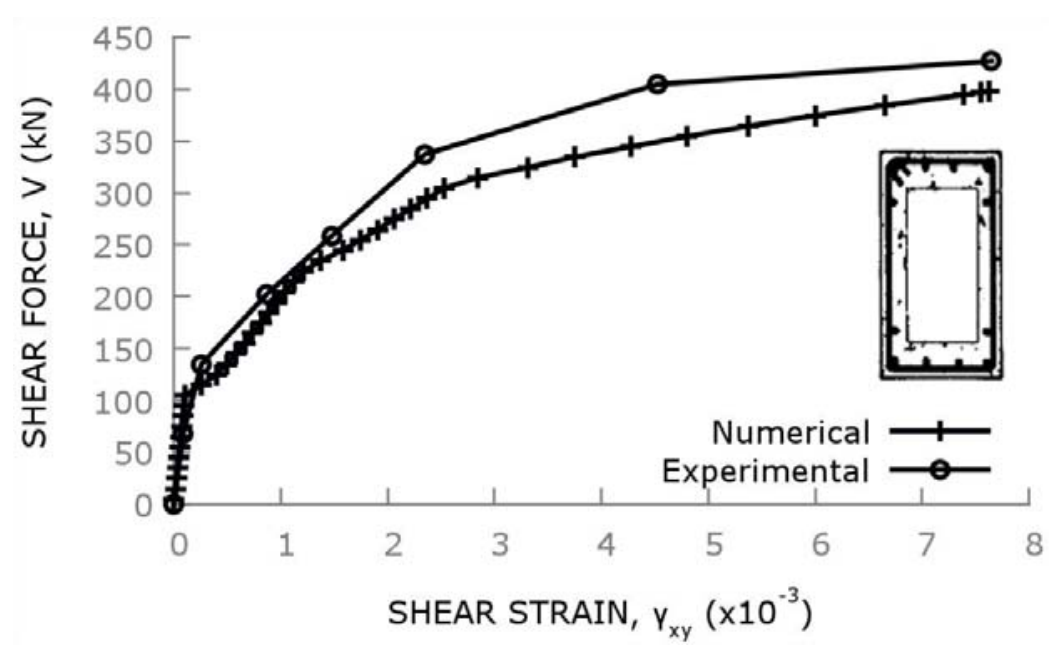

Figure 14: Analysis of shear beam (SM). 


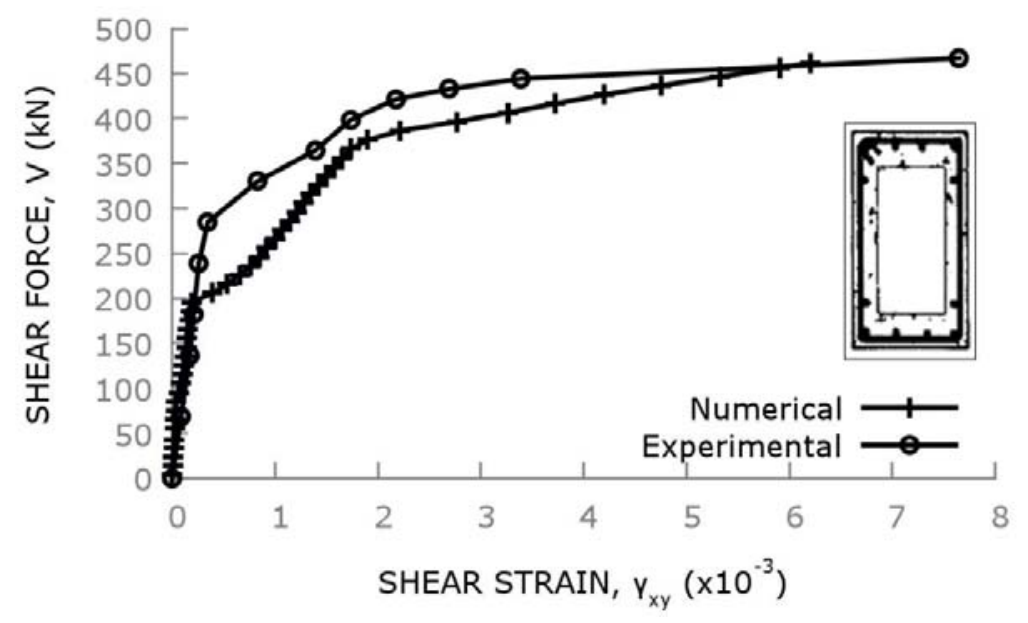

Figure 15: Analysis of shear beam (CF).

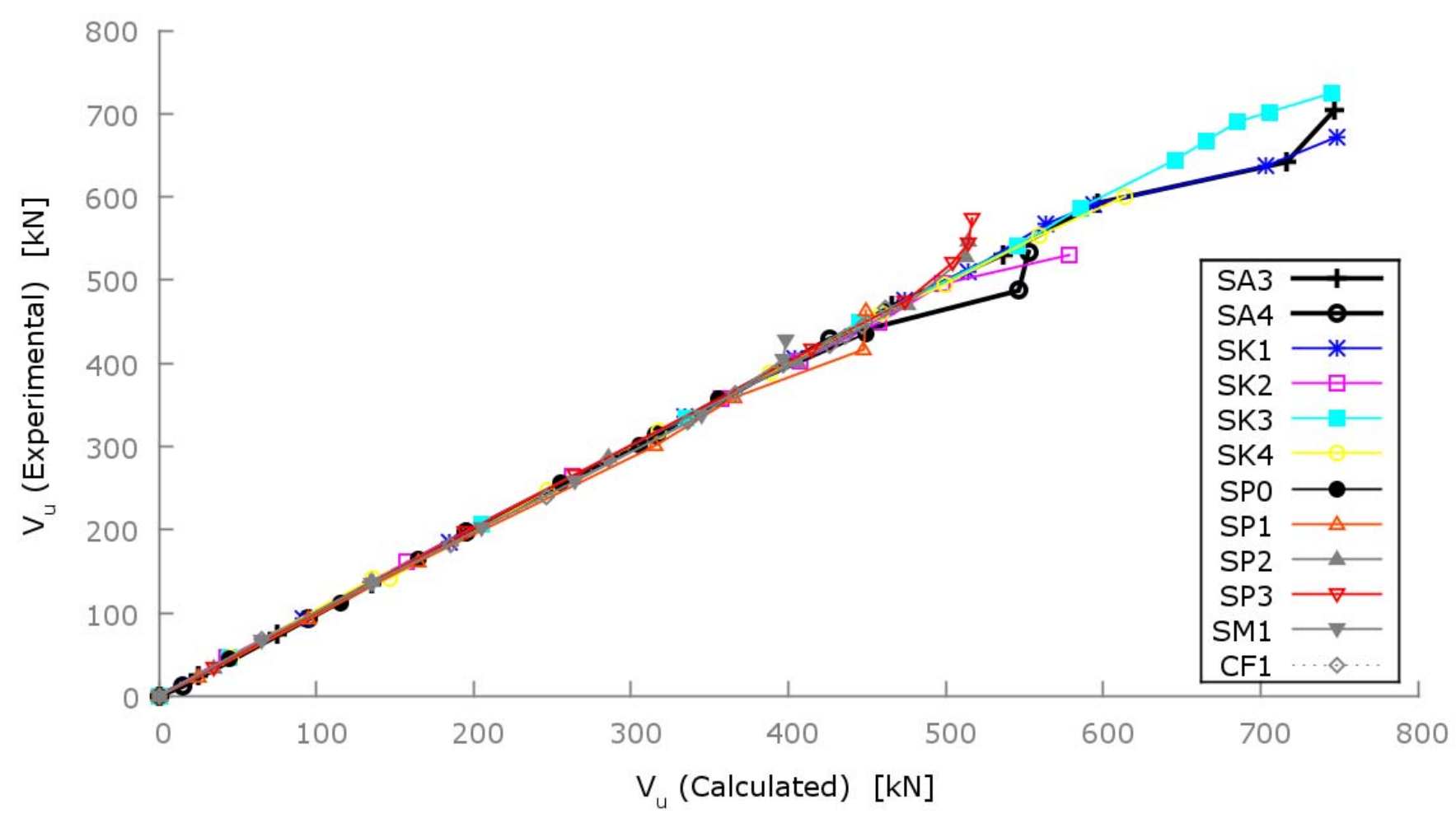

Figure 16: Comparison of experimental and predicted results.

Fig. 16 and the Tab. 2 show the evolution of the ultimate values of shear force calculated by this model and those observed experimentally.

It can be seen that the numerical model approaches the real behavior both before and after the cracking of the concrete, as well as the ultimate value of the shear force of all the beams studied.

However, in order to better appreciate the differences between the results obtained, it would be more judicious to proceed to further analysis by using a reliability method thus making it possible to better estimate the differences that may exist between the calculation and the experiment. 


\begin{tabular}{lccccc}
\hline BEAMS & EXPERIMENTAL & NUMERICAL & BEAMS & EXPERIMENTAL & NUMERICAL \\
SA3 & 716 & 745.0 & SP0 & 436 & 475.0 \\
SA4 & 534 & 532.5 & SP1 & 463 & 478.75 \\
SK1 & 672 & 750.0 & SP2 & 547 & 498.75 \\
SK2 & 530 & 575.0 & SP3 & 574 & 500.0 \\
SK3 & 725 & 733.75 & SM1 & 427 & 436.25 \\
SK4 & 601 & 608.75 & CF1 & 467 & 502.5 \\
\hline
\end{tabular}

Table 2: Experimental and numerical ultimate values of the shear force $\mathrm{Vu}(\mathrm{kN})$.

\section{RELIABILITY ASSESSMENT OF THE SHEAR LOADING BEHAVIOR}

$\mathrm{T}$

he sensitivity of the mechanical model to the different characteristics of the materials is introduced by using the random variables and failure scenarios, through a reliability method applied in this study for the different sections of the beams tested. This thus allows us to efficiently estimate the various reliability characteristics, according to each transition zone of the performance curve (limit state) on the shear loading behavior until the failure of the sections in the case of reinforced and/or prestressed concrete beam.

The random variables retained in this study are considered continuous, independent and they are represented by the vector X.

First, it is necessary to evaluate the nonlinear limit state function (implicit function) by an equivalent failure function, and which can be expressed for each transition zone as follows:

Zone 01 : phase before concrete cracking $\left(0 \leq \gamma \leq \gamma_{\text {fiss }}\right)$

$$
\mathrm{V}_{\text {fiss }}=\alpha_{1} \cdot \gamma_{\text {fiss }}
$$

Zone 02 : post cracking phase and before plasticization of steels $\left(\gamma_{\text {fiss }} \leq \gamma \leq \gamma_{\text {plas }}\right)$

$$
\left(\mathrm{V}_{\text {plas }}-\mathrm{V}_{\text {fiss }}\right)=\alpha_{2} \cdot\left(\gamma_{\text {plas }} \gamma_{\text {fiss }}\right)
$$

Zone 03 : post plasticization phase of steels $\left(\gamma_{\text {plas }} \leq \gamma \leq \gamma_{r}\right)$

$$
\left(\mathrm{V}_{r}-\mathrm{V}_{\text {plas }}\right)=\alpha_{3} \cdot\left(\gamma_{r}-\gamma_{\text {plas }}\right)
$$

In this problem, we are looking for a performance function making it possible to characterize the three transition zones of the limit state curve, where can for example express the performance function of the beam section (SA3) in the form of a function of polynomial limit state which can be represented as follows:

$$
G\left(X_{1}, X_{2}\right)=X_{1}+0.0002 X_{2}^{3}+0.0034 X_{2}^{2}+0.0426 X_{2}-1.7298
$$

where:

$$
\begin{aligned}
& X_{1}=V \\
& X_{2}=2 \cdot\left(\frac{\gamma_{r}-\gamma}{\gamma_{r}}\right)
\end{aligned}
$$


After having chosen the surface of polynomial responses, it will be used through several calls of the limit state function by the reliability calculation code, following an approach (FORM/SORM) making it possible to determine the position of the most probable point of failure and to estimate the reliability index for each transition zone of the performance function in a reduced centered space.

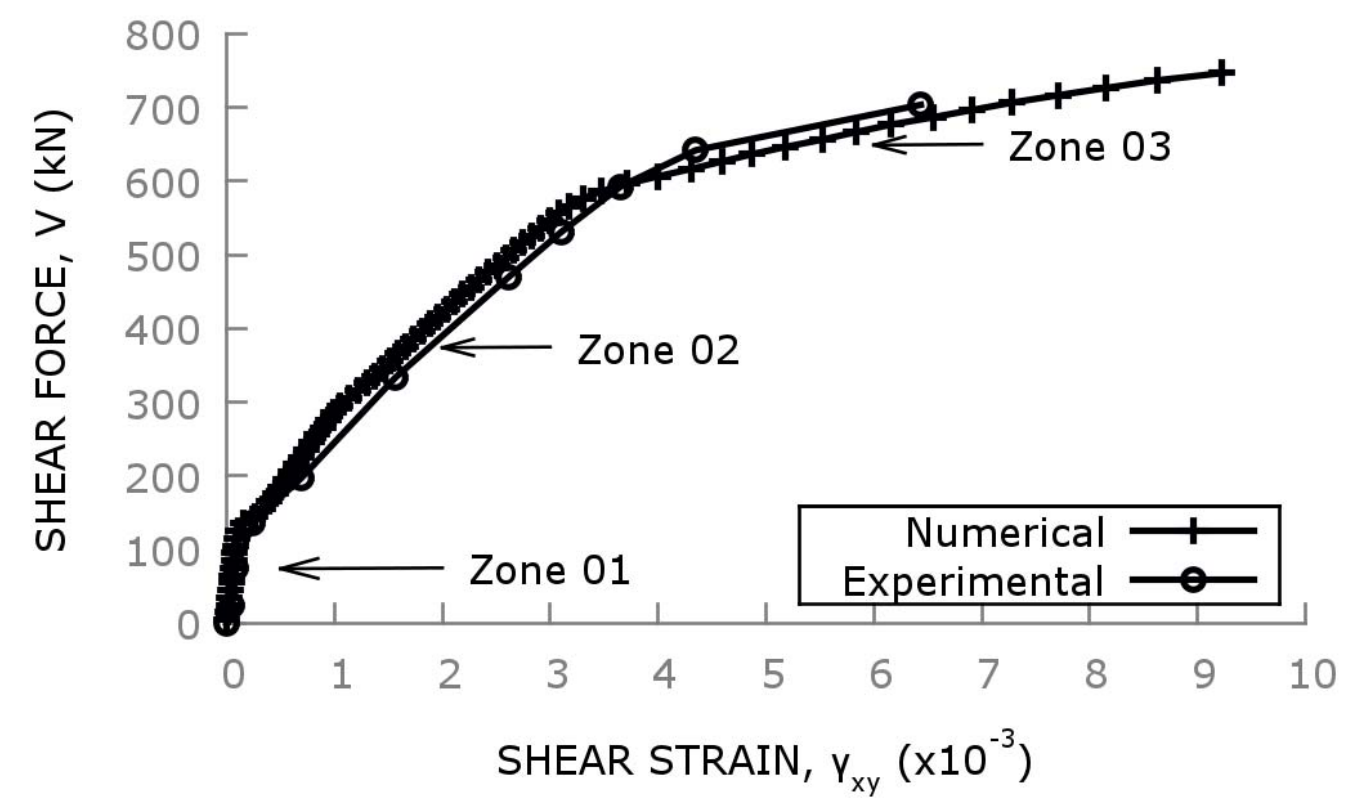

Figure 17: Limit state in physical space $\mathrm{G}(V, \gamma)$ of the beam section (SA3).

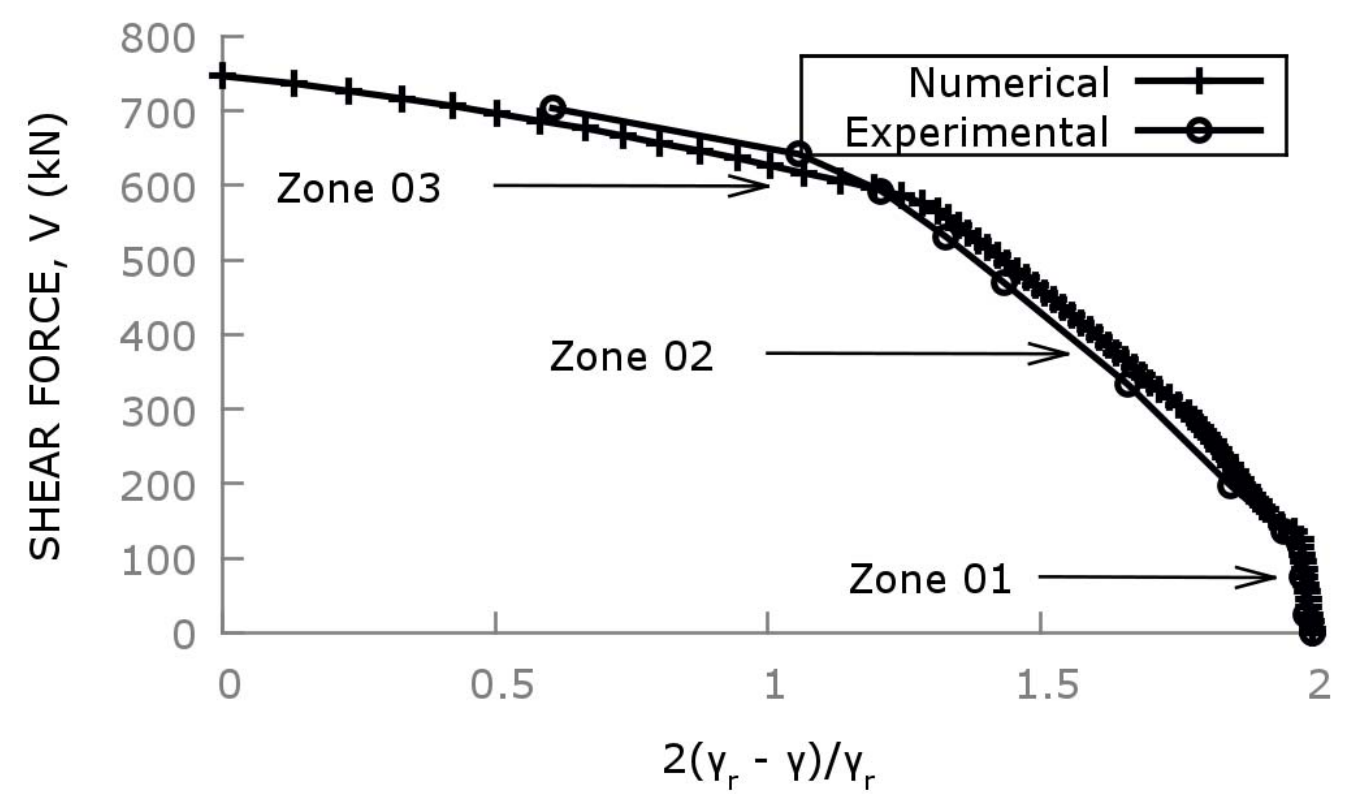

Figure 18: Performance function in physical space of the beam section (SA3).

Basic and output random variables in the limit state, their laws of random distributions are modeled as given in the Tab. 3. And for the other parameters (remaining input variables), they are considered deterministic.

We have performed a coupling between our reliability modeling and the implementation of the nonlinear calculation taking into account the loading shear behavior, and the limit state chosen as a performance function is a function which links the shear force and the shear strains corresponding to it, and taking as an example the limit state function of the (SA3) type beam section shown in the Fig. 19 in the reduced centered space. 


\begin{tabular}{|c|c|c|c|c|c|c|}
\hline BEAMS & $\begin{array}{c}\text { VECTOR } \\
\mathrm{X}\end{array}$ & $\begin{array}{c}\text { RANDOM } \\
\text { VARIABLES }\end{array}$ & TYPE & $\begin{array}{c}\text { DISTRIBUTION } \\
\text { LAW }\end{array}$ & $\operatorname{MEAN} \mu_{X}^{N}$ & $\begin{array}{c}\text { COEFFICIENT } \\
\text { OF VARIATION } \\
(\mathrm{COV})\end{array}$ \\
\hline \multirow{5}{*}{ SA3 } & $\mathrm{X}_{1}$ & V & Load & Normal & 340.8798077 & 0.10 \\
\hline & $\mathrm{X}_{2}^{\prime}$ & $\gamma$ & Resistance & Normal & $1.608293732 \times 10^{-3}$ & 0.10 \\
\hline & $\mathrm{X}_{3}$ & $\mathrm{E}_{c}$ & Resistance & Normal & 37620000 & 0.10 \\
\hline & $\mathrm{X}_{4}$ & $\varepsilon_{b 0}$ & Resistance & Normal & 0.0028 & 0.10 \\
\hline & $\mathrm{X}_{1}$ & $\mathrm{~V}$ & Load & Normal & 280.4348465 & 0.10 \\
\hline \multirow{3}{*}{ SA4 } & $\mathrm{X}_{2}^{\prime}$ & $\gamma$ & Resistance & Normal & $1.469326912 \times 10^{-3}$ & 0.10 \\
\hline & $\mathrm{X}_{3}$ & $\mathrm{E}_{c}$ & Resistance & Normal & 37620000 & 0.10 \\
\hline & $\mathrm{X}_{4}$ & $\varepsilon_{b 0}$ & Resistance & Normal & 0.0028 & 0.10 \\
\hline \multirow{5}{*}{ SK1 } & $\mathrm{X}_{1}$ & $\mathrm{~V}$ & Load & Normal & 364.1120197 & 0.10 \\
\hline & $\mathrm{X}_{2}^{\prime}$ & $\gamma$ & Resistance & Normal & $1.673839467 \times 10^{-3}$ & 0.10 \\
\hline & $\mathrm{X}_{3}$ & $\mathrm{E}_{c}$ & Resistance & Normal & 33000000 & 0.10 \\
\hline & $\mathrm{X}_{4}$ & $\varepsilon_{b 0}$ & Resistance & Normal & 0.00225 & 0.10 \\
\hline & $\mathrm{X}_{1}$ & $\mathrm{~V}$ & Load & Normal & 283.1132093 & 0.10 \\
\hline \multirow{3}{*}{ SK2 } & $\mathrm{X}_{2}^{\prime}$ & $\gamma$ & Resistance & Normal & $1.59049967 \times 10^{-3}$ & 0.10 \\
\hline & $\mathrm{X}_{3}$ & $\mathrm{E}_{c}$ & Resistance & Normal & 33000000 & 0.10 \\
\hline & $\mathrm{X}_{4}$ & $\varepsilon_{b 0}$ & Resistance & Normal & 0.00225 & 0.10 \\
\hline \multirow{5}{*}{ SK3 } & $\mathrm{X}_{1}$ & $\mathrm{~V}$ & Load & Normal & 365.359418 & 0.10 \\
\hline & $\mathrm{X}_{2}^{\prime}$ & $\gamma$ & Resistance & Normal & $1.560761406 \times 10^{-3}$ & 0.10 \\
\hline & $\mathrm{X}_{3}$ & $\mathrm{E}_{c}$ & Resistance & Normal & 33481000 & 0.10 \\
\hline & $\mathrm{X}_{4}$ & $\varepsilon_{b 0}$ & Resistance & Normal & 0.0022 & 0.10 \\
\hline & $\mathrm{X}_{1}$ & $\mathrm{~V}$ & Load & Normal & 312.336953 & 0.10 \\
\hline \multirow{3}{*}{ SK4 } & $\mathrm{X}_{2}$ & $\gamma$ & Resistance & Normal & $1.50661078 \times 10^{-3}$ & 0.10 \\
\hline & $\mathrm{X}_{3}$ & $\mathrm{E}_{c}$ & Resistance & Normal & 33000000 & 0.10 \\
\hline & $\mathrm{X}_{4}$ & $\varepsilon_{b 0}$ & Resistance & Normal & 0.0022 & 0.10 \\
\hline \multirow{5}{*}{ SP0 } & $\mathrm{X}_{1}$ & $\mathrm{~V}$ & Load & Normal & 229.8279712 & 0.10 \\
\hline & $\mathrm{X}_{2}^{\prime}$ & $\gamma$ & Resistance & Normal & $1.51393884 \times 10^{-3}$ & 0.10 \\
\hline & $\mathrm{X}_{3}$ & $\mathrm{E}_{c}$ & Resistance & Normal & 35460000 & 0.10 \\
\hline & $\mathrm{X}_{4}$ & $\varepsilon_{b 0}$ & Resistance & Normal & 0.0023 & 0.10 \\
\hline & $\mathrm{X}_{1}$ & $\mathrm{~V}$ & Load & Normal & 229.3812147 & 0.10 \\
\hline \multirow{3}{*}{ SP1 } & $\mathrm{X}_{2}^{\prime}$ & $\gamma$ & Resistance & Normal & $1.550932824 \times 10^{-3}$ & 0.10 \\
\hline & $\mathrm{X}_{3}$ & $\mathrm{E}_{c}$ & Resistance & Normal & 35000000 & 0.10 \\
\hline & $\mathrm{X}_{4}$ & $\varepsilon_{b 0}$ & Resistance & Normal & 0.0023 & 0.10 \\
\hline \multirow{5}{*}{ SP2 } & $\mathrm{X}_{1}$ & $\mathrm{~V}$ & Load & Normal & 264.6198399 & 0.10 \\
\hline & $\mathrm{X}_{2}^{\prime}$ & $\gamma$ & Resistance & Normal & $1.607561042 \times 10^{-3}$ & 0.10 \\
\hline & $\mathrm{X}_{3}$ & $\mathrm{E}_{c}$ & Resistance & Normal & 34000000 & 0.10 \\
\hline & $\mathrm{X}_{4}$ & $\varepsilon_{b 0}$ & Resistance & Normal & 0.002 & 0.10 \\
\hline & $\mathrm{X}_{1}$ & $\mathrm{~V}$ & Load & Normal & 259.5594739 & 0.10 \\
\hline \multirow{3}{*}{ SP3 } & $\mathrm{X}_{2}^{\prime}$ & $\gamma$ & Resistance & Normal & $1.630069451 \times 10^{-3}$ & 0.10 \\
\hline & $\mathrm{X}_{3}$ & $\mathrm{E}_{c}$ & Resistance & Normal & 33000000 & 0.10 \\
\hline & $\mathrm{X}_{4}$ & $\varepsilon_{b 0}$ & Resistance & Normal & 0.002 & 0.10 \\
\hline \multirow{5}{*}{ SM1 } & $\mathrm{X}_{1}$ & $\mathrm{~V}$ & Load & Normal & 204.2503351 & 0.10 \\
\hline & $\mathrm{X}_{2}$ & $\gamma$ & Resistance & Normal & $1.482089057 \times 10^{-3}$ & 0.10 \\
\hline & $\mathrm{X}_{3}$ & $\mathrm{E}_{c}$ & Resistance & Normal & 33000000 & 0.10 \\
\hline & $\mathrm{X}_{4}$ & $\varepsilon_{b 0}$ & Resistance & Normal & 0.0024 & 0.10 \\
\hline & $\mathrm{X}_{1}$ & $\mathrm{~V}$ & Load & Normal & 230.661821 & 0.10 \\
\hline \multirow{3}{*}{ CF1 } & $\mathrm{X}_{2}$ & $\gamma$ & Resistance & Normal & $1.667889239 \times 10^{-3}$ & 0.10 \\
\hline & $\mathrm{X}_{3}$ & $\mathrm{E}_{c}$ & Resistance & Normal & 37200000 & 0.10 \\
\hline & $\mathrm{X}_{4}$ & $\varepsilon_{b 0}$ & Resistance & Normal & 0.003 & 0.10 \\
\hline
\end{tabular}

Table 3: Characteristic of random variables (base and output).

Taking into account the complexity of the mechanical model (taking account of mechanical nonlinearity), it is difficult to carry out the study by a direct coupling between the mechanical model and reliability. It is for this reason in order to assess the probability of failure, it is necessary to use the method of response surfaces (MRS) of the polynomial type. The determined response surfaces (Fig. 20) will allow us to approach the explicit limit state function, which is an implicit 
nonlinear function (known numerically from our nonlinear calculation), whose failure of the system is observed when $\mathrm{G}\left(\mathrm{X}_{1}, \mathrm{X}_{2}\right) \geq 0$.

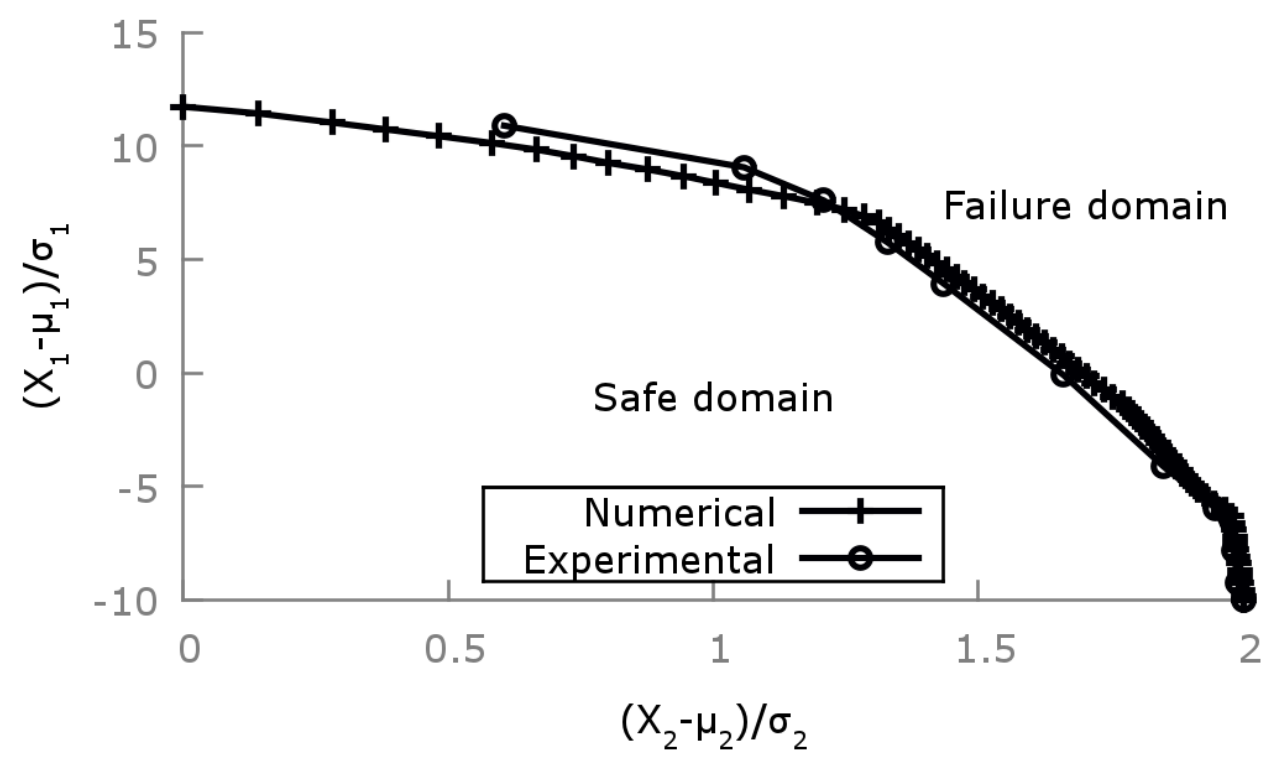

Figure 19: Limit state $G\left(X_{1}, X_{2}\right)$ in $2 \mathrm{D}$ in the reduced centered space of the beam section (SA3).

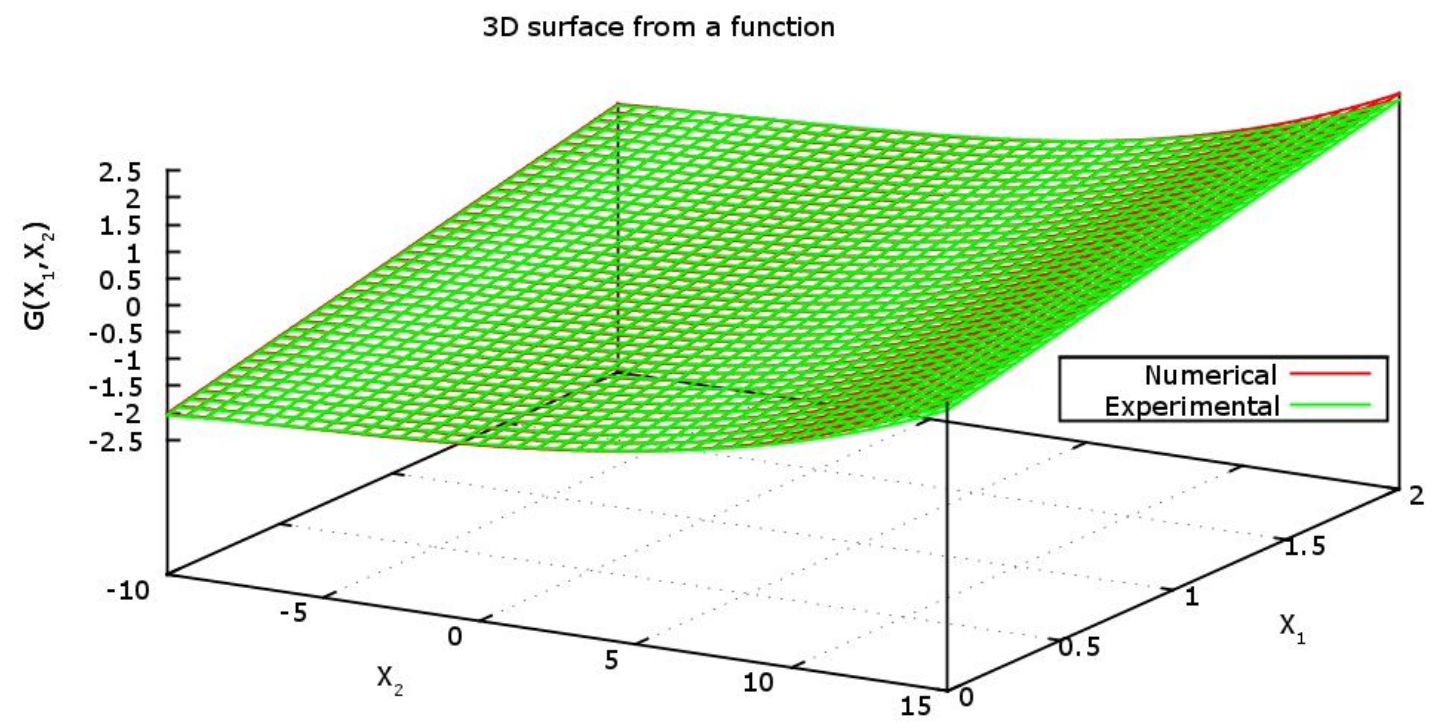

Figure 20: Limit state function $\mathrm{G}\left(\mathrm{X}_{1}, \mathrm{X}_{2}\right)$ in 3D of the beam section (SA3).

The calculation is carried out for mean values of the various random parameters, and where several reliability iterations have been taken into consideration to converge towards the design point.

The Rackwitz-Fiessler algorithm is used to perform the reliability study, and after analysis by mechanical reliability coupling by polynomial response surfaces (MRS), the HL-RF method allowed us to obtain the coordinates from the design point, the absolute values of the direction cosines of the random variables, as well as the reliability index and the probability of failure (Tab. 4) for each transition zone of the different limit state curves of the beams sections tested.

As shown in the Tab. 4, there is a very good agreement of the results of the mechano-reliability coupling using a response surface method expressed as a limit state function. 


\begin{tabular}{|c|c|c|c|c|c|c|}
\hline BEAMS & ZONES & $\begin{array}{l}\text { RELIABILITY } \\
\text { INDEX }\end{array}$ & $\begin{array}{l}\text { PROBABILITY } \\
\text { OF FAILURE }\end{array}$ & $\begin{array}{c}\text { DIRECTOR } \\
\text { COSINE } \\
(\mathrm{A} 1, \mathrm{~A} 2)\end{array}$ & $\begin{array}{c}\text { DESIGN POINT } \\
(\mathrm{U} 1, \mathrm{U} 2)\end{array}$ & $\begin{array}{c}\text { DESIGN POINT } \\
(\mathrm{X} 1, \mathrm{X} 2)\end{array}$ \\
\hline \multirow{4}{*}{ SA3 } & 01 & 6.1981 & $2.824 \times 10^{-10}$ & $(0.9486,-0.3162)$ & $(-5.8800,1.9600)$ & $(95.5249,1.5994)$ \\
\hline & 02 & 3.3448 & $4.117 \times 10^{-4}$ & $(-0.9119,-0.4103)$ & $(3.0501,1.3725)$ & $(243.8263,1.4338)$ \\
\hline & 03 & 7.6029 & $1.422 \times 10^{-14}$ & $(-0.9997,-0.0230)$ & $(7.6008,0.1754)$ & $(159.9053,0.6863)$ \\
\hline & 01 & 8.4909 & $1.0332 \times 10^{-17}$ & $(0.9738,-0.2272)$ & $(-8.2688,1.9293)$ & $(65.1281,1.6065)$ \\
\hline \multirow{3}{*}{ SA4 } & 02 & 4.9439 & $3.83264 \times 10^{-7}$ & $(-0.9635,-0.2676)$ & $(4.7635,1.3232)$ & $(136.4759,1.4348)$ \\
\hline & 03 & 7.6029 & $1.42234 \times 10^{-14}$ & $(-0.9997,-0.0230)$ & $(7.6008,0.1754)$ & $(159.9053,0.6863)$ \\
\hline & 01 & 3.1235 & $8.9363 \times 10^{-4}$ & $(0.7808,-0.6246)$ & $(-2.4390,1.9512)$ & $(204.4285,1.5914)$ \\
\hline \multirow{3}{*}{ SK1 } & 02 & 3.8065 & $7.04345 \times 10^{-5}$ & $(-0.9138,-0.4061)$ & $(3.4784,1.5459)$ & $(266.8430,1.5078)$ \\
\hline & 03 & 8.9349 & $2.13911 \times 10^{-19}$ & $(-0.9992,-0.0384)$ & $(8.9283,0.3433)$ & $(66.8240,1.0761)$ \\
\hline & 01 & 2.7059 & $3.40623 \times 10^{-3}$ & $(0.7474,-0.6643)$ & $(-2.0224,1.7977)$ & $(120.9005,1.6204)$ \\
\hline \multirow{3}{*}{ SK2 } & 02 & 2.6664 & $3.83404 \times 10^{-3}$ & $(-0.8849,-0.4657)$ & $(2.3595,1.2418)$ & $(274.1525,1.3566)$ \\
\hline & 03 & 9.4728 & $1.4511 \times 10^{-21}$ & $(-0.9993,-0.0363)$ & $(9.4665,0.3442)$ & $(28.9641,0.6067)$ \\
\hline & 01 & 5.2240 & $8.80556 \times 10^{-8}$ & $(0.9230,-0.3846)$ & $(-4.8221,2.0092)$ & $(141.2907,1.5900)$ \\
\hline \multirow{3}{*}{ SK3 } & 02 & 2.3491 & $9.42795 \times 10^{-3}$ & $(-0.6536,-0.7568)$ & $(1.5354,1.7778)$ & $(300.7293,1.4331)$ \\
\hline & 03 & 5.6622 & $7.49141 \times 10^{-9}$ & $(-0.9728,-0.2316)$ & $(5.5082,1.3114)$ & $(283.2090,0.7687)$ \\
\hline & 01 & 5.7507 & $4.42197 \times 10^{-9}$ & $(0.9388,-0.3442)$ & $(-5.3991,1.9796)$ & $(101.4725,1.5939)$ \\
\hline \multirow{3}{*}{ SK4 } & 02 & 3.0571 & $1.11773 \times 10^{-3}$ & $(-0.8999,-0.4359)$ & $(2.7512,1.3327)$ & $(222.9546,1.4375)$ \\
\hline & 03 & 9.6125 & $3.54862 \times 10^{-22}$ & $(-0.9998,-0.0190)$ & $(9.6107,0.1830)$ & $(21.5302,0.7287)$ \\
\hline & 01 & 5.0617 & $2.08389 \times 10^{-7}$ & $(0.9284,-0.3713)$ & $(-4.6996,1.8798)$ & $(81.5037,1.6163)$ \\
\hline \multirow{3}{*}{ SP0 } & 02 & 2.2965 & $1.08215 \times 10^{-2}$ & $(-0.8348,-0.5504)$ & $(1.9172,1.2641)$ & $(246.1723,1.1360)$ \\
\hline & 03 & 9.0856 & $5.30577 \times 10^{-20}$ & $(-0.9995,-0.0285)$ & $(9.0819,0.2594)$ & $(36.1524,0.7342)$ \\
\hline & 01 & 2.8491 & $2.1923 \times 10^{-3}$ & $(0.7348,-0.6782)$ & $(-2.0934,1.9324)$ & $(109.2482,1.5914)$ \\
\hline \multirow{3}{*}{ SP1 } & 02 & 4.0323 & $2.77117 \times 10^{-5}$ & $(-0.9279,-0.3726)$ & $(3.7418,1.5027)$ & $(177.8183,1.3292)$ \\
\hline & 03 & 9.0748 & $6.01284 \times 10^{-20}$ & $(-0.9988,-0.0475)$ & $(9.0644,0.4316)$ & $(39.5503,0.5601)$ \\
\hline & 01 & 3.1235 & $8.9223 \times 10^{-4}$ & $(0.6401,-0.7682)$ & $(-1.9995,2.3995)$ & $(144.3488,1.5007)$ \\
\hline \multirow{3}{*}{ SP2 } & 02 & 3.2279 & $6.2352 \times 10^{-4}$ & $(-0.9494,-0.3138)$ & $(3.0647,1.0131)$ & $(232.5354,1.4703)$ \\
\hline & 03 & 7.3386 & $1.12074 \times 10^{-13}$ & $(-0.9934,-0.1146)$ & $(7.2902,0.8411)$ & $(129.3096,0.7071)$ \\
\hline & 01 & 3.4873 & $2.43984 \times 10^{-4}$ & $(0.8320,-0.5547)$ & $(-2.9015,1.9343)$ & $(167.6967,1.5887)$ \\
\hline \multirow{2}{*}{ SP3 } & 02 & 4.2637 & $1.0082 \times 10^{-5}$ & $(-0.9438,-0.3303)$ & $(4.0243,1.4085)$ & $(208.8308,1.3920)$ \\
\hline & 03 & 7.5889 & $1.63048 \times 10^{-14}$ & $(-0.9970,-0.0766)$ & $(7.5665,0.5820)$ & $(116.4464,0.6541)$ \\
\hline \multirow{4}{*}{ SM1 } & 01 & 5.1072 & $1.63712 \times 10^{-7}$ & $(0.9284,-0.3713)$ & $(-4.7419,1.8967)$ & $(74.2200,1.6097)$ \\
\hline & 02 & 4.6074 & $1.9523 \times 10^{-6}$ & $(-0.9474,-0.3197)$ & $(4.3654,1.4733)$ & $(115.3302,1.4417)$ \\
\hline & 03 & 8.6089 & $3.66322 \times 10^{-18}$ & $(-0.9993,-0.0363)$ & $(8.6032,0.3128)$ & $(49.9285,0.6267)$ \\
\hline & 01 & 3.1235 & $8.9363 \times 10^{-4}$ & $(0.7808,-0.6246)$ & $(-2.4390,1.9512)$ & $(118.4773,1.5931)$ \\
\hline \multirow{2}{*}{ CF1 } & 02 & 5.4176 & $3.03553 \times 10^{-8}$ & $(-0.9776,-0.2102)$ & $(5.2965,1.1390)$ & $(134.5162,1.5123)$ \\
\hline & 03 & 7.1983 & $2.99974 \times 10^{-13}$ & $(-0.9987,-0.04993)$ & $(9.1022,0.4551)$ & $(37.7926,0.9045)$ \\
\hline
\end{tabular}

Table 4: Results of the mechano-reliability analysis of the different sections of the beams tested.

Reliability index in the probabilistic model as histogram

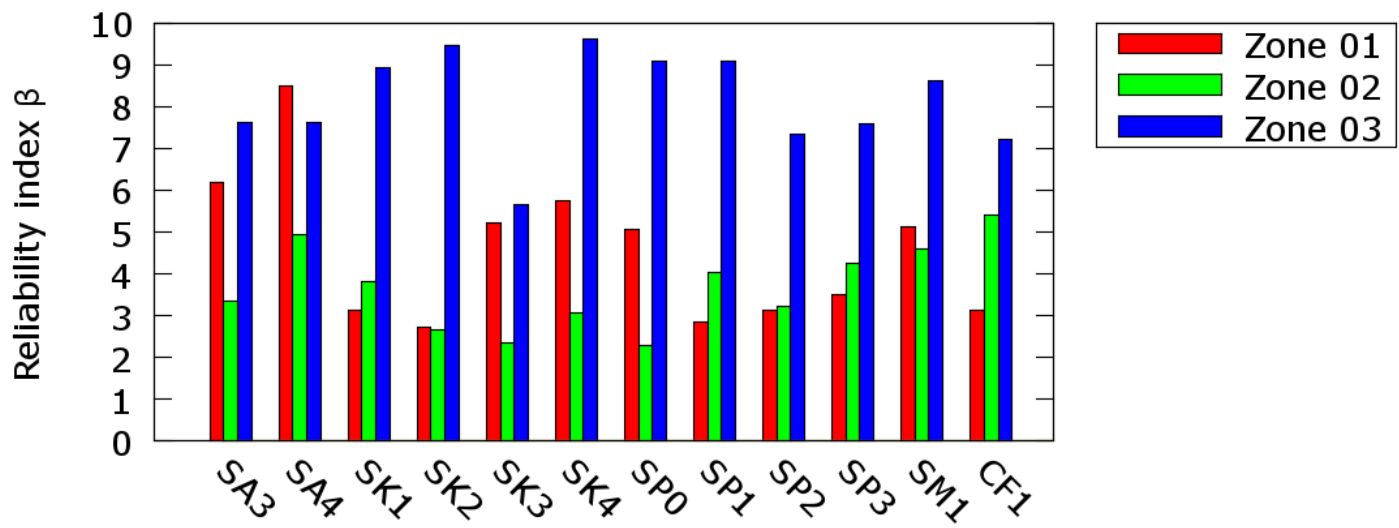

Figure 21: Reliability indices from numerical analysis. 


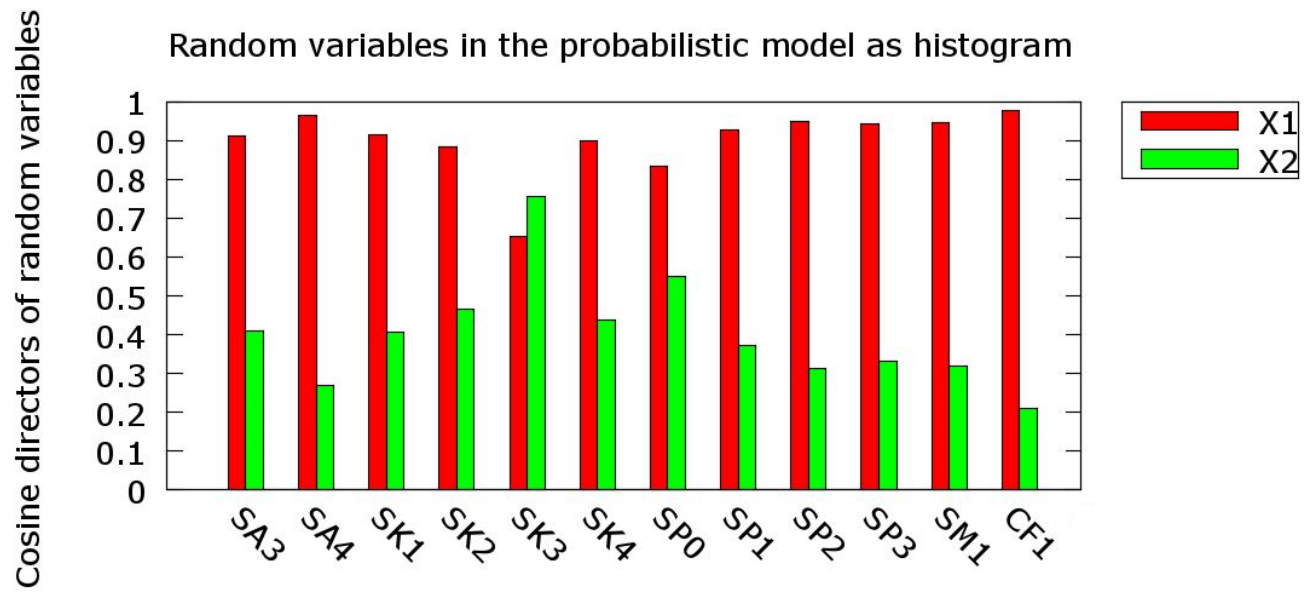

Figure 22: Absolute value of the direction cosines of the random variables $\left(\mathrm{X}_{1}, \mathrm{X}_{2}\right)$ at the level of zone 02 .

\begin{tabular}{|c|c|c|c|c|c|c|}
\hline \multirow[b]{2}{*}{ BEAMS } & \multirow[b]{2}{*}{ ZONES } & \multicolumn{2}{|c|}{ NUMERICAL RESULTS } & \multicolumn{2}{|c|}{ EXPERIMENTAL RESULTS } & \multirow[b]{2}{*}{$\begin{array}{c}\text { DEVIATIONS } \\
(\%)\end{array}$} \\
\hline & & $\begin{array}{l}\text { Reliability } \\
\text { index }\end{array}$ & $\begin{array}{c}\text { Probability of } \\
\text { failure }\end{array}$ & $\begin{array}{l}\text { Reliability } \\
\text { index }\end{array}$ & Probability of failure & \\
\hline \multirow{3}{*}{ SA3 } & 01 & 6.1981 & $2.824 \times 10^{-10}$ & 6.1888 & $3.051 \times 10^{-10}$ & 0.1502 \\
\hline & 02 & 3.3448 & $4.117 \times 10^{-4}$ & 3.2419 & $5.936 \times 10^{-4}$ & 3.17 \\
\hline & 03 & 7.6029 & $1.422 \times 10^{-14}$ & 7.8920 & $1.491 \times 10^{-15}$ & 3.66 \\
\hline \multirow{3}{*}{ SA4 } & 01 & 8.4909 & $1.0332 \times 10^{-17}$ & 7.9632 & $8.82851 \times 10^{-16}$ & 6.6267 \\
\hline & 02 & 4.9439 & $3.83264 \times 10^{-7}$ & 4.6886 & $1.37962 \times 10^{-6}$ & 5.4451 \\
\hline & 03 & 7.6029 & $1.42234 \times 10^{-14}$ & 8.0074 & $5.80751 \times 10^{-16}$ & 5.0515 \\
\hline \multirow{3}{*}{ SK1 } & 01 & 3.1235 & $8.9363 \times 10^{-4}$ & 3.1073 & $9.44094 \times 10^{-4}$ & 0.5213 \\
\hline & 02 & 3.8065 & $7.04345 \times 10^{-5}$ & 3.9492 & $3.91536 \times 10^{-5}$ & 3.6133 \\
\hline & 03 & 8.9349 & $2.13911 \times 10^{-19}$ & 8.5254 & $7.84242 \times 10^{-18}$ & 4.8032 \\
\hline \multirow{3}{*}{ SK2 } & 01 & 2.7059 & $3.40623 \times 10^{-3}$ & 2.6901 & $3.57194 \times 10^{-3}$ & 0.5873 \\
\hline & 02 & 2.6664 & $3.83404 \times 10^{-3}$ & 2.7736 & $2.2604 \times 10^{-3}$ & 3.8650 \\
\hline & 03 & 9.4728 & $1.4511 \times 10^{-21}$ & 9.2484 & $1.21946 \times 10^{-20}$ & 2.4263 \\
\hline \multirow{3}{*}{ SK3 } & 01 & 5.2240 & $8.80556 \times 10^{-8}$ & 5.1280 & $1.4728 \times 10^{-7}$ & 1.8720 \\
\hline & 02 & 2.3491 & $9.42795 \times 10^{-3}$ & 2.3380 & $9.6942 \times 10^{-3}$ & 0.4747 \\
\hline & 03 & 5.6622 & $7.49141 \times 10^{-9}$ & 5.8133 & $3.28927 \times 10^{-9}$ & 2.5992 \\
\hline \multirow{3}{*}{ SK4 } & 01 & 5.7507 & $4.42197 \times 10^{-9}$ & 5.7254 & $5.18532 \times 10^{-9}$ & 0.4418 \\
\hline & 02 & 3.0571 & $1.11773 \times 10^{-3}$ & 3.0121 & $1.29718 \times 10^{-3}$ & 1.4939 \\
\hline & 03 & 9.6125 & $3.54862 \times 10^{-22}$ & 9.6801 & $1.927 \times 10^{-22}$ & 0.6983 \\
\hline \multirow{3}{*}{ SP0 } & 01 & 5.0617 & $2.08389 \times 10^{-7}$ & 5.0298 & $2.46802 \times 10^{-7}$ & 0.6342 \\
\hline & 02 & 2.2965 & $1.08215 \times 10^{-2}$ & 2.3303 & $9.89517 \times 10^{-3}$ & 1.4504 \\
\hline & 03 & 9.0856 & $5.30577 \times 10^{-20}$ & 9.5366 & $7.81774 \times 10^{-22}$ & 4.7291 \\
\hline \multirow{3}{*}{ SP1 } & 01 & 2.8491 & $2.1923 \times 10^{-3}$ & 2.8352 & $2.29008 \times 10^{-3}$ & 0.4902 \\
\hline & 02 & 4.0323 & $2.77117 \times 10^{-5}$ & 4.2204 & $1.22388 \times 10^{-5}$ & 4.4569 \\
\hline & 03 & 9.0748 & $6.01284 \times 10^{-20}$ & 9.4266 & $2.19861 \times 10^{-21}$ & 3.7319 \\
\hline \multirow{3}{*}{ SP2 } & 01 & 3.1235 & $8.9223 \times 10^{-4}$ & 3.0904 & $9.99664 \times 10^{-4}$ & 1.0710 \\
\hline & 02 & 3.2279 & $6.2352 \times 10^{-4}$ & 3.3684 & $3.78024 \times 10^{-4}$ & 4.1711 \\
\hline & 03 & 7.3386 & $1.12074 \times 10^{-13}$ & 7.5445 & $2.3724 \times 10^{-14}$ & 2.7291 \\
\hline \multirow{3}{*}{ SP3 } & 01 & 3.4873 & $2.43984 \times 10^{-4}$ & 3.4649 & $2.65198 \times 10^{-4}$ & 0.6464 \\
\hline & 02 & 4.2637 & $1.0082 \times 10^{-5}$ & 4.4168 & $5.02669 \times 10^{-6}$ & 3.4663 \\
\hline & 03 & 7.5889 & $1.63048 \times 10^{-14}$ & 7.9138 & $1.25506 \times 10^{-15}$ & 4.1054 \\
\hline \multirow{3}{*}{ SM1 } & 01 & 5.1072 & $1.63712 \times 10^{-7}$ & 5.0981 & $1.71334 \times 10^{-7}$ & 0.1784 \\
\hline & 02 & 4.6074 & $1.9523 \times 10^{-6}$ & 4.6817 & $1.42903 \times 10^{-6}$ & 1.5870 \\
\hline & 03 & 8.6089 & $3.66322 \times 10^{-18}$ & 8.9083 & $2.56737 \times 10^{-19}$ & 3.4777 \\
\hline \multirow{3}{*}{ CF1 } & 01 & 3.1235 & $8.9363 \times 10^{-4}$ & 3.1287 & $8.77926 \times 10^{-4}$ & 0.1662 \\
\hline & 02 & 5.4176 & $3.03553 \times 10^{-8}$ & 5.0133 & $2.6845 \times 10^{-7}$ & 8.0645 \\
\hline & 03 & 7.1983 & $2.99974 \times 10^{-13}$ & 7.6272 & $1.23246 \times 10^{-14}$ & 5.6232 \\
\hline
\end{tabular}

Table 5: Comparison of the deviations of the mechano-reliability analysis of the different sections of beams. 
The Fig. 22 presents the respective values of the variables introduced to the modeling on the reliability of the numerical model at the level of zone 02. The direction cosine of the random variables of the beam's sections tested allows us to measure the influence of each of the design variables, which gives us information on the sensitivity of the design point and the reliability index to each standardized random variable. The few differences observed are related to the fact that the load case differs depending on the type of beam tested, and where we can generally see that their increase in absolute value induces better reliability. The results of the comparison of the deviations resulting from the mechano-reliability analysis on the various tested beams are presented in the Tab. 5 and the Fig. 21, where it is possible to observe a very good consistency numerical results compared to those provided by the experiment at the level of the different transition zones.

\section{Reliability index in the probabilistic model as histogram}

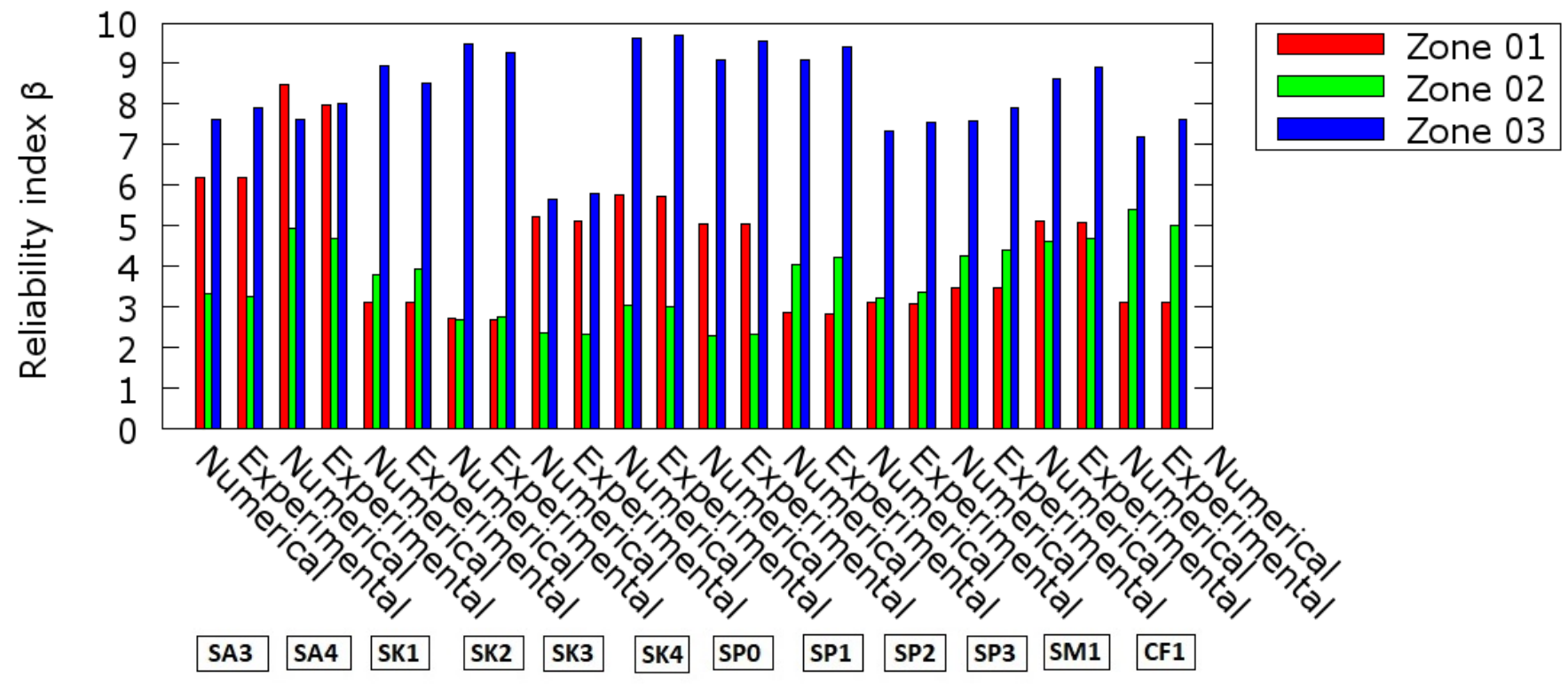

Figure 23: Difference in reliability indices between calculation and test.

The reliability study shows the importance of taking into account the three transition zones of the performance curve in order to appreciate the deviations of the distortion evolution curve $\gamma_{\text {moy }}$ with the shear force $\mathrm{V}$ that may exist between calculation and testing. In fact, we can see generally from the Tab. 5 that in the phase before concrete cracking the difference is practically negligible, on the other hand a small difference in the post cracking phase (before steel yielding) and the post yielding steel phase between the calculation and the testing is observed.

It can be seen from the Tab. 5 and from the Fig. 23 that the design point of the limit state function (performance function) is given by the second transition zone, they which gives the lowest reliability index. These reliability results allow us to show us the most significant area of the performance curve in estimating the design point.

\section{CONCLUSION}

he real constitutive laws of concrete, passive and active reinforcements were taken into account by the various models of behavior presented (Grelat, Sargin, BAEL99, BPEL99) allowing to correctly reproduce their stressstrain envelope curves, and they have been implemented in order to deal with the shear loading behavior of reinforced and/or prestressed concrete beam sections, which makes it possible to best estimate their actual displacements. Thus, the model used satisfactorily describes the behavior of reinforced and/or prestressed concrete beams whether in terms of resistance or of displacement, in the different phases of the behavior (before cracking of the concrete, post cracking and before steels yielding, post steels yielding).

The limit state function (performance) obtained by the numerical model is not explicitly possible, we then proposed a technique for estimating the performance function, then we reduced ourselves to using a coupling technique by 
polynomial response surface in order to be able to use the reliability methods (FORM/SORM). The reliability analysis approach having been carried out mainly because of the uncertainties of the various phenomena brought into play during the dimensioning of the structures, we carried out this approach by building the performance function (limit state) according to three transition zones resulting from the real behavior of the beams tested in the shear loading in order to take into account a possible feared event which could cause its failure.

The method of coupling by response surface of the different transition zones proposed, allowed us to efficiently approximate the real limit state surface by a performance function, which evolves in three distinct phases resulting from the nonlinear behavior in the shear loading until the breakage of the reinforced and/or prestressed concrete beam sections. The results obtained from this study allowed us to determine the probability of failure and all the reliability characteristics (reliability indices, direction cosines, performance point coordinates) for each transition zone of the limit state function (performance) in order to perform a reliability analysis of the numerical model.

\section{ACKNOWLEDGEMENTS}

7 he authors wish to thank the Algerian Ministry of higher education and scientific research for funding the University education research project (PRFU - $\mathrm{N}^{\circ}$ A01L02UN150120180004) and Tassili Project (PHC - 43940NJ).

\section{DECLARATION OF INTEREST STATEMENT}

$\mathrm{n}$ behalf of all authors, the corresponding author states that there is no conflict of interest.

\section{Notation}

$\varphi(\varepsilon)$ : Defines the actual behavior of the materials,

$\mathrm{E}_{\mathrm{b} 0}$ : Concrete modulus at the origin,

$\varepsilon_{\mathrm{b} 0}$ : Peak strain corresponding to $\mathrm{f}_{\mathrm{cj}}$,

$\mathrm{f}_{\mathrm{cj}}$ : Concrete compressive strength at the age $\mathrm{j}$,

$\mathrm{k}_{\mathrm{b}}$ : Dimensionless parameters, sargin law,

$\grave{\mathrm{k}}_{\mathrm{b}}$ : Dimensionless parameters, sargin law,

$\mathrm{f}_{\mathrm{tj}}$ : Concrete tensile strength,

$\varepsilon_{\text {rt }}:$ Steel ultimate strain,

$\varepsilon_{\mathrm{bt}}$ : Concrete fiber tensile strain,

$\varepsilon_{f t}$ : Tension deformation corresponding to $f_{t j}$,

$\varepsilon_{s 1}$ : Deformation corresponding to the end of the plastic bearing,

$\varepsilon_{s 2}$ : Deformation corresponding to the end of the firming,

$\varepsilon_{s u}$ : Breaking strain,

$E_{a}:$ Steel longitudinal module,

$\varepsilon_{e}$ : Deformation elastic limit of the steel,

$\sigma_{e}:$ Elastic yield stress of steel,

$\varepsilon_{u}$ : Ultimate deformation of steel,

$E_{a}$ : Is the Young's modulus of steel at the origin,

$\sigma_{e}$ : Is the conventional elastic limit at $2 \%$,

0,7. $\sigma_{e}$ : Is constraint or stops the linear diagram,

$\sigma_{p}$ : Is the stress in the prestressing steel,

$\varepsilon_{p}$ : Is the deformation in the prestressing steel, 
$E_{p}:$ Is Young's modulus at the origin,

$f_{\text {peg }}:$ Is the conventional elastic limit at $0.1 \%$,

$0,9 \cdot f_{\text {peg }}$ : Is constraint or stops the linear diagram,

$1,06 . f_{\text {peg }}:$ Is the breaking stress,

$\varepsilon_{\mathrm{su}}:$ Failure strain,

$\varepsilon_{e}:$ Steel yield strain,

$\sigma_{e}:$ Steel yield stress,

$\varepsilon_{u}$ : Steel ultimate strain,

$\mathrm{E}_{\mathrm{a}}$ : Steel modulus at the origin,

$\varepsilon_{\mathrm{X}}$ : Gravity center strain,

$N_{b t r}:$ Number of concrete trapezes,

$N_{S}$ : Number of passive reinforcing beds,

$A_{a i}:$ Passive steel bed area,

$y_{a i}$ : Passive steel bed dimension relative to the oy reference axis,

$\mathrm{y}_{\mathrm{i}}$ : Lower trapezoidal ordinate,

$\mathrm{y}_{\mathrm{i}+1}$ : Upper trapezoid ordinate,

$\mathrm{b}_{\mathrm{i}}$ : The lower abscissa of trapezoid along the $\mathrm{x}$ axis,

$\mathrm{b}_{\mathrm{i}+1}$ : The upper abscissa of trapezoid along the $\mathrm{x}$ axis,

$\mathrm{Fk}$ and $\mathrm{Fk} 1$ : The normal forces acting on layer $\mathrm{k}$ in both sections,

Gk-1 and Gk : The resulting sliding forces on the lower and upper faces of the $k$ layer,

$\mathrm{Vk}$ : The share of the shear force balanced by the layer $\mathrm{k}$,

$\mathrm{m}$ : The number of layers of concrete,

$X:$ Basic random vector,

$\mathrm{G}:$ Failure function or limit state function,

$\Phi$ : The normal law distribution function reduced centered (mean 0 and standard deviation 1),

$\mathrm{m}_{\mathrm{R}}$ : Means strength,

$\mathrm{m}_{\mathrm{S}}:$ Means loads,

$\sigma_{\mathrm{R}}:$ Standard deviations of the strength,

$\sigma_{\mathrm{S}}:$ Standard deviations of the loads,

$\mathrm{P}^{*}$ : Point of the most probable failure,

$u^{*}:$ Design point,

$\beta^{*}:$ Reliability index associated with the design point,

$g, g_{U}:$ Failure function in $\mathrm{U}$ space,

$\alpha^{(\mathrm{k})}$ : Vector cosine directors,

$\beta$ : Reliability index associated with $P_{F}$,

$P_{F}$ : Probability of failure.

\section{REFERENCES}

[1] Collins, M.P. (1978). Towards a Rational Theory for RC Members in Shear, J. Struct. Div., 104(4), pp. 649-666.

[2] Vecchio, F.J., Collins, M.P. (1982). The response of reinforced concrete to in-plane shear and normal stresses. University of Toronto, Department of Civil Engineering, Publication No.82-03.

[3] Vecchio, F.J., Collins, M.P. (1986). The modified compression-field theory for reinforced concrete elements subjected to shear, ACI Struct. J., 83(2), pp. 219-231.

[4] Bažant, Z.P., Kazemi, M.T. (1991). Size effect on diagonal shear failure of beams without stirrups, ACI Struct. J., 88(3), pp. 268-276.

[5] Bentz, E.C., Vecchio, F.J., Collins, M.P. (2006). Simplified modified compression field theory for calculating shear strength of reinforced concrete elements, ACI Struct. J., 103(4), pp. 614-624.

[6] Carbone, V.I., Giordano, L., Mancini, G. (2001). Design of RC membrane elements, Struct. Concr., 2(4), pp. $213-223$.

[7] Hsu, TTC., Zhang, L. (1997). Nonlinear analysis of membrane elements by fixed-angle softened-truss model, ACI Struct. J., 94(5), pp. 483-491. 
[8] Hsu, T.T.C. (1996). Toward a unified nomenclature for reinforced concrete theory, J. Struct. Eng., 122(3), pp. 275283. DOI: 10.1061/(ASCE)0733-9445(1996)122:3(275).

[9] Miguel, P.F., Navarro-Gregori, J., Fernández-Prada, M.A., Bonet, J.L. (2013). A simplified method to predict the ultimate shear stress of reinforced concrete membrane elements, Eng. Struct., 49, pp. 329-344.

DOI: 10.1016/j.engstruct.2012.11.009.

[10] Rahal, K.N. (2010). Shear-transfer strength of reinforced concrete, ACI Struct. J., 107(4), pp. 419-426.

[11] Rahal, K.N. (2008). Simplified design and capacity calculation of shear strength in reinforced concrete membrane elements. Eng. Struct., 30(10), pp. 2782-2791. DOI: 10.1016/j.engstruct.2008.03.002.

[12] Vecchio, F.J. (2000). Disturbed stress field model for reinforced concrete: formulation, J. Struct. Eng., 126(9), pp. 1070-1077. DOI: 10.1061/(ASCE)0733-9445(2000)126:9(1070).

[13] Vecchio, F.J. (2001). Disturbed stress field model for reinforced concrete: implementation, J. Struct. Eng., 127(1), pp. 12-20. DOI: 10.1061/(ASCE)0733-9445(2001)127:1(12).

[14] Kachi, M.S., Fouré, B., Bouafia, Y., Muller, P. (2006). L'effort trenchant dans la modélisation du comportement jusqu' à rupture des pouters en béton armé et précontraint. Revue Européenne de Génie Civil, 10(10), pp. 1235-1264. DOI: $10.1080 / 17747120.2006 .9692914$.

[15] Grelat, A. (1978). Nonlinear analysis of reinforced concrete hyperstatics frames. Doctoral thesis Engineer. University Paris VI.

[16] Nait-Rabah, O. (1990). Numerical simulation of nonlinear behavior of frames Space. Doctoral Thesis. Central School of Paris.

[17] Freudenthal, A.M. (1947). The safety of structures, Transactions of ASCE, 112(1), pp.125-159.

[18] Cornell, C.A. (1969). A Probability Based Structural Code, Journal of American Concrete Institute, 66(12), pp. 974 985.

[19] Hasofer, A.M. (1974). Reliability index and failure probability, J. Struct. Mech., 3(1), pp. 25-27. DOI: $10.1080 / 03601217408907254$.

[20] Mohamed, A.M., Lemaire, M. (1995). Linearized mechanical model to evaluate reliability of offshore structures, Structural Safety 17(3), pp. 167-193. DOI: 10.1016/0167-4730(95)00009-S.

[21] Rackwitz, R. (2001). Reliability analysis - a review and some perspectives, Structural Safety, 23(4), pp. 365-395. DOI: 10.1016/S0167-4730(02)00009-7.

[22] Benyahi, K., Bouafia, Y., Barboura, S., Kachi, M.S. (2018). Nonlinear analysis and reliability of metallic truss structures, Front. Struct. Civ. Eng., 12, pp. 577-593. DOI: 10.1007/s11709-017-0458-y.

[23] Jeong, J.P., Kang, D.H. (2019). Investigation on shear strain of reinforced concrete membrane panels subjected to pure shear, Advances in Mechanical Engineering, 11(8), pp. 1-12. DOI: 10.1177/1687814019869488.

[24] Filho, B., Bernardo, L., Horowitz B. (2020). Softened Variable Angle Truss Model (RA-STM): Model Description and Refinement/Optimization Proposals, KnE Engineering, 5(5), pp. 36-48. DOI: 10.18502/keg.v5i5.6909.

[25] Bernardo, L.F.A., Filho, B.M.V.C., Horowitz, B. (2020). Predicting the behavior of prestressed concrete membrane elements by refined rotating-angle softened-truss model with efficient solution procedure, Struct. Concr. J. fib., 21(3), pp. 934-948. DOI: 10.1002 /suco.201900481.

[26] Bernardo, L.F.A., Filho, B.M.VC., Horowitz, B. (2020). Refined efficient RA-STM procedure for RC membrane elements, Eng. Struct., 213. DOI: 10.1016/j.engstruct.2020. 110552.

[27] Bernardo, L.F.A., Filho, B.M.V.C., Horowitz, B. (2021). Predicting the Behavior of FRP-Strengthened RC Membrane Elements with Efficient Rotating-Angle Softened-Truss Model Procedure, Mater. Struct., 54.

DOI: $10.1617 / \mathrm{s} 11527-021-01631-y$.

[28] Bernardo, L.F.A., Lyrio A.R.B., Silva, J.R.B., Horowitz, B. (2018). Refined Softened Truss Model with Efficient Solution Procedure for Prestressed Concrete Membranes, J. of Struct. Eng., 144(6). DOI: 10.1061/(ASCE)ST.1943-541X.0002044.

[29] Bernardo, L.F.A., Cerquido, B.M.D., Silva, J.R.B., Horowitz, (2018). Efficient Refined rotating angle softened truss model procedure to analyze reinforced concrete membrane elements, Struct. Concr. J. fib., 19(6), pp.1971-1982. DOI: $10.1002 /$ suco.201800012.

[30] Silva, J.R.B. (2016). Efficient procedure for the analysis of reinforced concrete sections using the softened truss model, Master Thesis, Department of Civil Engineering, Federal University of Pernambuco, Recife, Brazil [in Portuguese].

[31] Bernardo, L., Sadieh, S. (2021). A Monotonic Smeared Truss Model to Predict the Envelope Shear Stress-Shear Strain Curve for Reinforced Concrete Panel Elements under Cyclic Shear, Applied Mechanics, 2(1), pp. 174-194.

DOI: $10.3390 /$ applmech2010011. 
[32] Schlune, H., Plos, M., Gylltoft, K. (2011). Safety formats for nonlinear analysis tested on concrete beams subjected to shear forces and bending moments, Eng. Struct., 33(8), pp. 2350-2356. DOI: 10.1016/j.engstruct.2011.04.008.

[33] Allaix, D.L., Carbone, V.I., Mancini, G. (2013). Global safety format for non-linear analysis of reinforced concrete structures, Struct. Concr., 14(1), pp. 29-42. DOI: 10.1002/suco.201200017.

[34] El Ghoulbzouri, A., Kissi, B., Khamlichi, A. (2015). Reliability analysis of reinforced concrete buildings: comparison between FORM and ISM, Procedia Eng., 114, pp. 650-657. DOI: 10.1016/j.proeng.2015.08.006.

[35] Olmati, P., Sagaseta, J., Cormie, P., Jones, A.E.K. (2017). Simplified reliability analysis of punching in reinforced concrete flat slab buildings under accidental actions, Eng. Struct., 130(1), pp. 83-98. DOI: $10.1016 /$ j.engstruct.2016.09.061.

[36] Słowik, M., Skrzypczak, I., Kotyniac, R., Kaszubskac, M. (2017). The application of a probabilistic method to the reliability analysis of longitudinally reinforced concrete beams, Procedia Eng., 193, pp. 273-280. DOI: $10.1016 /$ j.proeng.2017.06.214.

[37] Hadidi, A., Azar, B.F, Rafiee, A. (2017). Efficient response surface method for high-dimensional structural reliability analysis, Struct. Saf., 68, pp. 15-27. DOI: 10.1016/j. strusafe.2017.03.006.

[38] Rakoczy, A.M., Nowak, A.S. (2013). Reliability-based sensitivity analysis for prestressed concrete girder bridges, PCI Journal, 58(4), pp. 81-92. DOI: 10.15554/pcij.09012013.81.92.

[39] Roy, A., Robuschi, S., Hendriks, M.A., Belletti, B. (2016). Safety assessment of existing reinforced concrete beams using probabilistic methods at different levels, Key engineering materials, 711, pp. 958-965. DOI: 10.4028/www.scientific.net/KEM.711.958.

[40] Slobbe, A., Rózsás, Á., Allaix, D.L., Bigaj-van Vliet A. (2020). On the value of a reliability-based nonlinear finite element analysis approach in the assessment of concrete structures, Struct. Concr., 21(1), pp. 32-47. DOI: $10.1002 /$ suco.201800344.

[41] Grubišić, M., Ivošević, J., Grubišić, A. (2019). Reliability Analysis of Reinforced Concrete Frame by Finite Element Method with Implicit Limit State Functions, Buildings, 9(5). DOI: 10.3390/buildings9050119.

[42] Sargin, M. (1971). Stress-Strain relationship for concrete and the analysis of structural concrete sections. Solid Mechanics division, University of waterloo.

[43] Rules BAEL 91, revised 99 (1999). Technical rules for the design of reinforced concrete structures according to the limit states method. Publisher: Association Francaise de Normalisation.

[44] Rules BPEL91, revised 99 (1999). Technical design rules and calculation of works and structures prestressed concrete according to the limit states method. Publisher: Association Francaise de Normalisation.

[45] Atkinson, K. (1989). An Introduction to Numerical Analysis. John Wiley \& Sons Inc., 2nd edition, New York.

[46] Belarbie, A., Hsu, T.T.C. (1995). Constitutive low of softened concrete in biaxial tension-compression, ACI Struct. J., 92(5), pp. 562-573. 